\title{
SOX2 is a dose-dependent regulator of retinal neural progenitor competence
}

\author{
Olena V. Taranova, ${ }^{1,3}$ Scott T. Magness, ${ }^{1,3}$ B. Matthew Fagan, ${ }^{1}$ Yongqin $\mathrm{Wu}{ }^{2}$ Natalie Surzenko, ${ }^{1}$ \\ Scott R. Hutton, ${ }^{1}$ and Larysa H. Pevny ${ }^{1,4}$ \\ ${ }^{1}$ Department of Genetics and ${ }^{2}$ Neuroscience Center In Situ Hybridization Core Facility, University of North Carolina \\ Neuroscience Center, University of North Carolina at Chapel Hill, Chapel Hill, North Carolina 27599, USA
}

\begin{abstract}
Approximately $10 \%$ of humans with anophthalmia (absent eye) or severe microphthalmia (small eye) show haploid insufficiency due to mutations in SOX2, a SOXB1-HMG box transcription factor. However, at present, the molecular or cellular mechanisms responsible for these conditions are poorly understood. Here, we directly assessed the requirement for SOX2 during eye development by generating a gene-dosage allelic series of Sox 2 mutations in the mouse. The Sox 2 mutant mice display a range of eye phenotypes consistent with human syndromes and the severity of these phenotypes directly relates to the levels of SOX2 expression found in progenitor cells of the neural retina. Retinal progenitor cells with conditionally ablated Sox2 lose competence to both proliferate and terminally differentiate. In contrast, in Sox 2 hypomorphic/null mice, a reduction of SOX2 expression to $<40 \%$ of normal causes variable microphthalmia as a result of aberrant neural progenitor differentiation. Furthermore, we provide genetic and molecular evidence that SOX2 activity, in a concentration-dependent manner, plays a key role in the regulation of the NOTCH1 signaling pathway in retinal progenitor cells. Collectively, these results show that precise regulation of SOX2 dosage is critical for temporal and spatial regulation of retinal progenitor cell differentiation and provide a cellular and molecular model for understanding how hypomorphic levels of SOX2 cause retinal defects in humans.
\end{abstract}

[Keywords: SOX2; allelic series; retinal progenitor identity; dosage regulation; anopthalmia, microapthalmia]

Supplemental material is available at www.genesdev.org.

Received January 6, 2006; revised version accepted March 8, 2006.

Seven main classes of retinal cell types (rod, cone, bipolar, horizontal, amacrine, ganglion, and Müller glial cells) are produced from a pool of multipotent retinal progenitor cells (RPC). The overall size of the retina, and the proportion of each of these cell types contained therein is essential for proper visual processing. To ensure that the adult retina forms appropriately during development, RPCs transition through states of developmental competence by coordinating cell cycle exit and cell fate specification to generate an ordered array of uniquely fated cell populations (Dyer and Cepko 2001; Fujita 2003; Pearson and Doe 2004; Zhang et al. 2004; Kageyama et al. 2005). When these processes are disrupted, as observed in some cases of human microphthalmia and anophthalmia (Zigman and Paxhia 1988; Loosli et al. 1998; Fantes et al. 2003; Driver et al. 2005; Fitzpatrick and van Heyningen 2005; Labadie et al. 2005; O'Brien et al. 2005; Ragge et al. 2005a,b; Xu et al. 2005), vision is severely compromised. Identifying the molecular mechanisms that allow some progenitors to continually divide yet promote neighboring cells to stop dividing and differentiate at appropriate times during develop-

\footnotetext{
${ }^{3}$ These authors contributed equally to this work.

${ }^{4}$ Corresponding author.

E-MAIL larysa_pevny@med.unc.edu; FAX (919) 966-9605.

Article and publication are at http://www.genesdev.org/cgi/doi/10.1101/ gad.1407906
}

ment is pivotal to the understanding of both normal and defective retinal development.

It has recently been shown that mutations in $S O X 2$ a SOXB1-HMG box transcription factor whose expression universally marks neural stem and progenitor cells throughout the CNS including the neural retina (Collignon et al. 1996; Zappone et al. 2000; D'Amour and Gage 2003; Ellis et al. 2004; Ferri et al. 2004), are associated with retinal and ocular malformations in humans. The resulting haploid insufficiency at the SOX2 locus occurs in $\sim 10 \%$ of human individuals with anophthalmia or severe microphthalmia (Fantes et al. 2003; Fitzpatrick and van Heyningen 2005; Hagstrom et al. 2005; Ragge et al. 2005a,b; Zenteno et al. 2005). Most mutations identified to date are point mutations leading to truncations of SOX2, while a smaller class of mutations includes microdeletions and missense point mutations. Interestingly, all mutations produce hypomorphic conditions, where residual SOX2 expression and function are still preserved, albeit at lower levels, leading to the highly variable severity of the clinical phenotype. In this regard, the SOX2 mutations in humans and the clinical consequence of reduced functional levels of SOX2 suggest a dosage-dependent role for SOX2 during retinal progenitor differentiation.

To date, the importance of SOX2 in the nervous system has been highlighted by misexpression and domi- 
nant interfering studies in mouse cell lines, Xenopus, and chick embryos, which suggests that SOX2 maintains neural progenitor identity (Mizuseki et al. 1998; Kishi et al. 2000; Bylund et al. 2003; Graham et al. 2003; Pevny and Placzek 2005; Van Raay et al. 2005). However, the lethality of Sox2-null mutant mice at the preimplantation stage (Avilion et al. 2003) combined with the overlap in expression and potential functional redundancy of the three highly related SOXB1 factors (SOX1, SOX2, and SOX3) in CNS progenitors (Collignon et al. 1996; Pevny et al. 1998; Weiss et al. 2003; Rizzoti et al. 2004; Tanaka et al. 2004) have precluded genetic evaluation of the specific role of SOX2 in neural progenitor cells.

Unlike the extensive overlap of their expression in the rest of the CNS, SOXB1 factors display unique patterns of expression in the developing eye (Kamachi et al. 1998, 2001; Nishiguchi et al. 1998; Uchikawa et al. 1999, 2003; Le et al. 2002). SOX1, SOX2, and SOX3 are initially expressed in the anterior neural plate and invaginating optic vesicle. However, during the formation of the optic cup, SOX1 and SOX3 are down-regulated, while SOX2 is maintained and restricted to neural retinal cells (Kamachi et al. 1998, 2001; Le et al. 2002). Thus, the selective expression of SOX2, and not SOX1 or SOX3, in the neural retina, coupled with cellular and molecular parallels between ventricular zone and retinal CNS progenitor differentiation, provides an ideal in vivo model system to evaluate the unique contribution of SOX2 in neural progenitor populations (Collignon et al. 1996; Kamachi et al. 1998; Nishiguchi et al. 1998; Le et al. 2002; Uchikawa et al. 2003; Blackshaw et al. 2004).

To dissect out the retinal-specific roles of SOX2 and to determine the effect of SOX2 dosage on these roles, here we report the examination of systematic dosage reduction of SOX2 on retinal progenitor differentiation using conditional/null, compound hypomorphic/null, and heterozygous/null and wild-type mice. First, we show that conditional ablation of SOX 2 in the mouse retina causes the complete loss of neural progenitor competence to divide and differentiate. Second, and in contrast with complete ablation of SOX2, hypomorphic levels of SOX2 expression trigger aberrant retinal progenitor differentiation, resulting in variable microphthalmic phenotypes. In addition, using two independent approaches we demonstrate that SOX2, acting as a transcription factor, mediates its effects by directly regulating the expression levels of NOTCH1. These studies provide direct cellular and molecular evidence that alterations in the levels of SOX2 regulate the choice between maintenance of progenitor cell identity and differentiation. Moreover, these data reveal a molecular basis for retinal defects in humans, which present as anophthalmia and microphthalmia syndromes, as a consequence of hypomorphic levels of SOX2.

\section{Results}

SOX2 defines retinal progenitor cells

Previous studies have shown that SOX2 expression marks proliferating neural progenitors and is down-regu- lated in the CNS ventricular zone concomitant with their differentiation (Ellis et al. 2004; Ferri et al. 2004; Rizzoti et al. 2004; Tanaka et al. 2004). We therefore addressed whether SOX2 expression is regulated in a similar dynamic manner in RPCs. RPC differentiation results in the formation of discrete layers; progenitor cells are retained in the outer retinoblast layer (RBL) (arrow in Fig. 1B), while cells that exit the cell cycle are located in the inner ganglion cell layer (GCL) (arrow in Fig. 1D). Upon exiting the cell cycle, retinal progenitors differentiate into six defined neuronal cell types in a precise temporal and spatial manner (Cepko et al. 1996; Reh and Fischer 2001). Retinal ganglion cells (RGCs) are generated first, followed by overlapping phases of development for horizontal cells, cones, amacrine cells, rods, and bipolar cells. Using a Sox $2^{E G F P}$-reporter mouse line in which the SOX2 coding region is replaced by enhanced green fluorescent protein (EGFP) such that EGFP fluorescence recapitulates SOX2 expression (Ellis et al. 2004) we show that, as in the CNS ventricular zone, SOX2 and EGFP (Fig. 1A,E) expression in the embryonic retina coincides with markers of cell proliferation such as Proliferating Cell Nuclear Antigen (PCNA) (Fig. 1B,F). However, in contrast to CNS ventricular zone progenitors that also express SOX1 and SOX3, retinal neural progenitors exclusively express SOX2 (Fig. 1 C,G). Coincident with retinal cell differentiation, SOX2 (and EGFP) expression is down-regulated such that its expression is mutually exclusive of the general neuronal marker neuron-specific class III $\beta$ TUBULIN ( $\beta$ TUBULIN III) in the GCL (Fig. 1D,H). Subsequently, SOX2 (and EGFP) (Supplementary Fig. 6) is not detected in cells expressing specific markers associated with each of the mature retinal cell types including NEUROFILAMENT, a marker of RGCs and horizontal cells (Fig. 1I,L), RHODOPSIN, a marker of rod cells (Fig. 1J,M), and Protein Kinase $\mathrm{C} \alpha$ (PKC), a marker of bipolar cells (Fig. 1K,N). Consistent with the expression pattern of Sox 2 in the chick (Le et al. 2002), SOX2 is maintained in a small subset of cells identified as displaced amacrines by the coexpression of ISLET1 (Fig. 1O,R) and CALRETININ (Fig. 1P,S). In contrast to its down-regulation in post-mitotic neuronal cells, SOX2 is maintained in Müller glia, a nonneuronal cell type of the mature retina, marked by Cellular Retinal-Binding Protein (CRALBP) (Fig. 1Q,T) (Eisenfeld et al. 1985) and Glial Fibrillary Acidic Protein (GFAP) (data not shown) expression.

These analyses demonstrate that SOX2 expression in both the neural retina and ventricular zone of the CNS is inversely correlated with the progression of neuronal differentiation, suggesting that there is a shared mechanism regulated by SOX2.

\section{A dosage-dependent role for SOX2 during retinal progenitor differentiation}

To analyze the effects of decreasing levels of SOX2 in neural progenitor cells, we generated an allelic series of Sox2 mutations in the mouse including a null $\left(\operatorname{Sox} 2^{E G F P}\right)$, a conditional null (Sox $\left.2^{C O N D}\right)$, and two hy- 

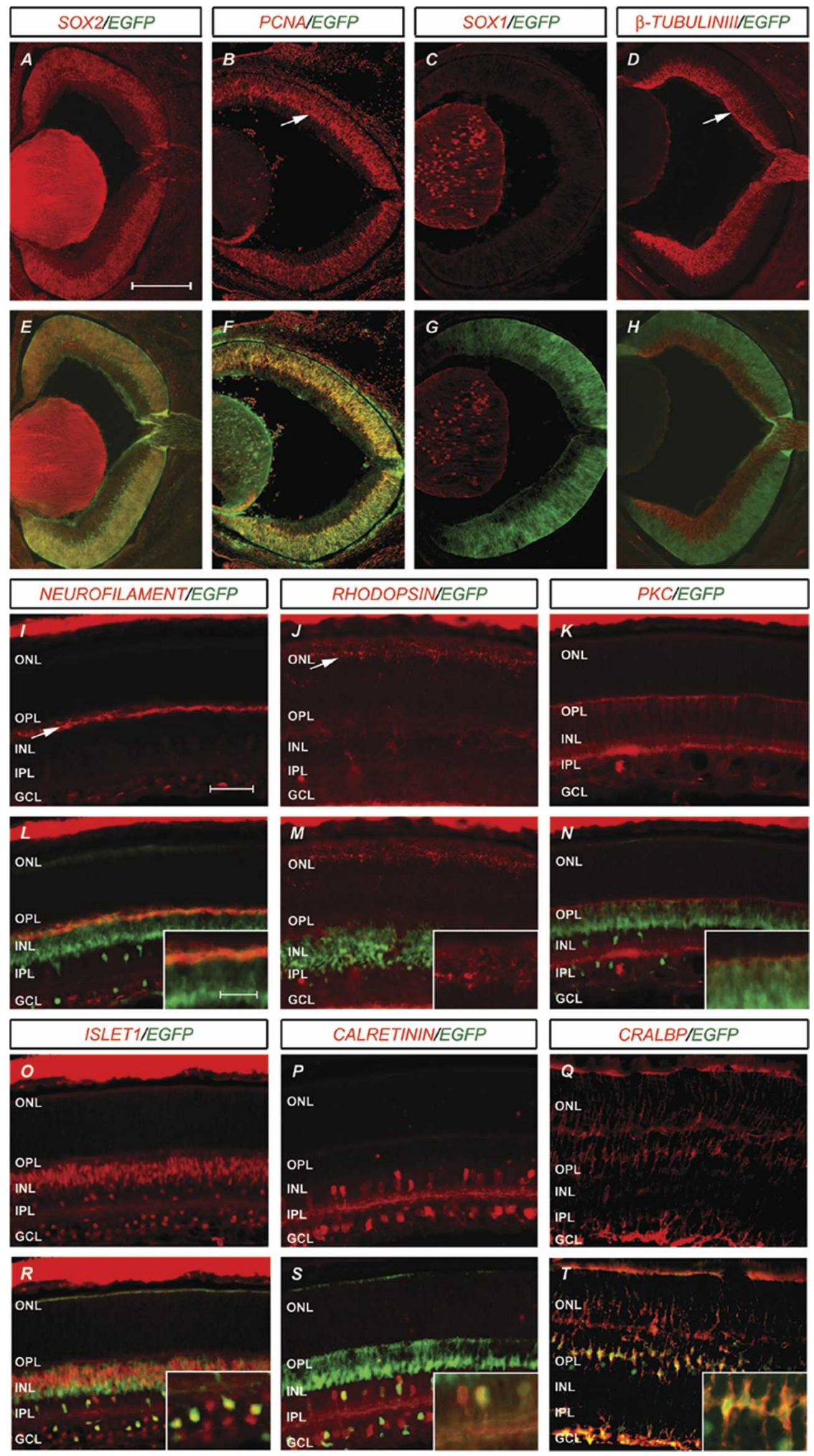
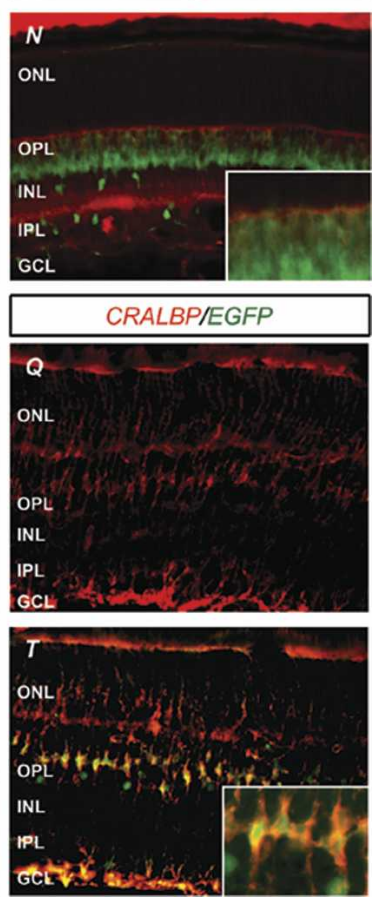

Figure 1. SOX2 defines progenitor cell population in the retina. SOX2 expression was evaluated using Sox $2^{+/ E G F P}$ (green) mice (Ellis et al. 2004) and specific antibodies (red). (A,E,B,F) At E15.5, Sox2-EGFP fluorescence, SOX2, and PCNA are coexpressed in the RBL. $(C, G) S O X 1$ expression is restricted to lens cells. Sox $2^{E G F P}$ is down-regulated in differentiating neurons, as marked by $\beta$ TUBULINIII $(D, H)$ NEUROFILAMENT $(I, L \text {; inset in } L \text {; arrow in } I)_{;}$ RHODOPSIN $(J, M \text {; inset in } M \text {; arrow in } J)_{;}$ and PKC $(K, N$; inset in $N)$. Sox2-EGFP expression was maintained in a subpopulation of amacrine cells identified by ISLET 1 $(O, R$; inset in $R)$ and CALRETININ $(P, S$; inset in $S \mid$, and Müller glia stained for CRALBP $(Q, T$; inset in $T)$. (ONL) outer nuclear layer; $(\mathrm{OPL})$; outer plexiform layer (INL); inner nuclear layer (IPL); inner plexiform layer (GCL) ganglion cell layer. Bars: $A-H, 200 \mu \mathrm{m} ; I-T, 50 \mu \mathrm{m} ; I-T$ (insets), $20 \mu \mathrm{m}$. pomorphic (Sox $2^{L P}$ and $\operatorname{Sox} 2^{I R}$ ) alleles. Sox $2^{E G F P}$ is a null allele in which the Sox2 ORF has been substituted with an EGFP expression cassette (Ellis et al. 2004). The Sox $2^{C O N D}$ allele contains the Sox2 ORF flanked by loxP sites such that CRE-mediated recombination results in removal of the entire SOX2 coding sequence and generates a null allele $\left(S_{o x} 2^{\triangle C O N D}\right)($ Fig. $2 \mathrm{~A}, \mathrm{~B})$, and $\operatorname{Sox}^{L P}$ and Sox $2^{I R}$ were constructed by the insertion of $P G K-n e O-$ loxP and IRESdsRED-loxP-flanked-PGKneo expression cassettes, respectively, 3' of the Sox2 ORF (Fig. 2A,C,D). 
Figure 2. Generation of allelic series of mouse Sox2 locus. (A) Targeting vector introduced two lox $P$ sites flanking the Sox2 promoter and mRNA coding regions. Homologous recombination of this vector at the Sox2 genomic locus in ES cells resulted in the generation of two alleles. Complete insertion of the vector generated the Sox $2^{C O N D}$ allele, while partial incorporation of the $3^{\prime}$ part of this vector generated the Sox $2^{L P}$ allele, which contains only the $3^{\prime}$ insertion, but not the $5^{\prime} \operatorname{lox} P$ site. CRE-driven recombination in Sox $2^{+/ C O N D}$; ACTB-Cre mice (in ACTB mice CRE recombinase is expressed in the female germline) resulted in deletion of the Sox2 promoter and mRNA coding region as well as the Neo cassette, generating a null allele $\left(\operatorname{Sox} 2^{\triangle C O N D}\right)$. $(B)$ The DNA recombination events were confirmed by Southern blot analysis of mouse tail DNA. $(C)$ In targeting vector B, the 3' UTR of Sox2 was replaced by internal ribosome entry site (IRES) and dsRED2 coding sequence followed by a Neo cassette flanked with two loxP sites. The incorporation of the insertion into Sox2 locus generated the $\operatorname{Sox}^{I R}$ allele. The restriction enzymes used were AvrII (A), NheI (N), EcoRI (RI), SalI (S), SpeI (Sp), EcoRV (V). (D) Segregation of the alleles in the mouse lines was confirmed by Southern blotting with the P1 after EcoRI digest. (E) Quantification of pups and embryos of each genotype recovered from indicated breedings.
A
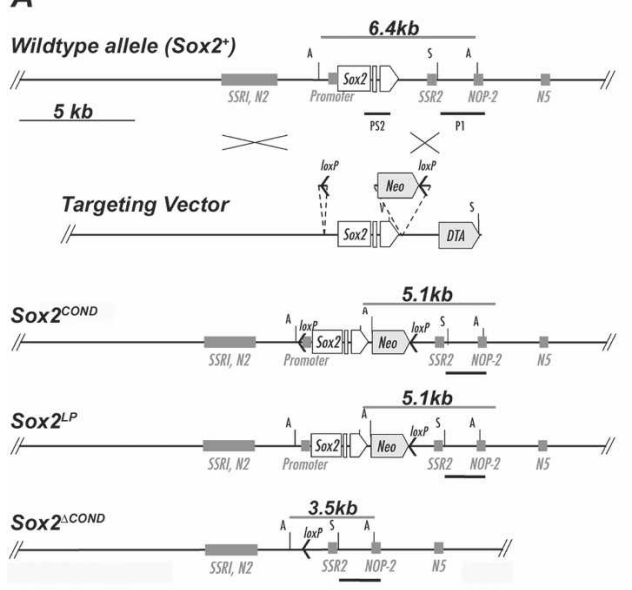

C

Wildtype allele (Sox2+)
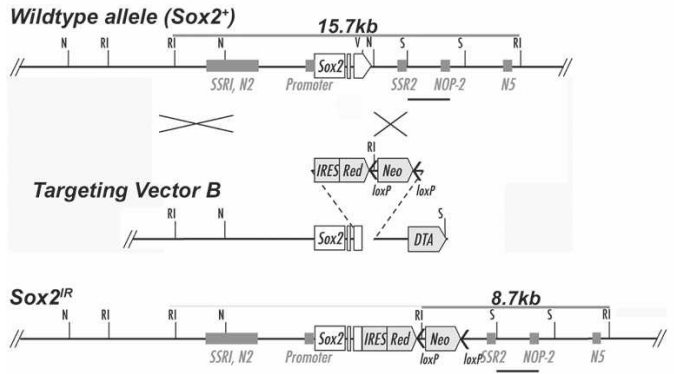

E
$B$

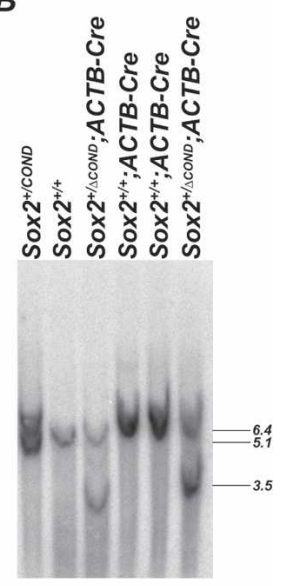

$D$

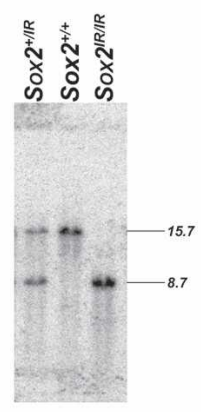

\begin{tabular}{|c|c|c|c|c|}
\hline Sox $2^{+/ R} \times \operatorname{Sox} 2^{+\pi / R}$ & $+/ t$ & Sox $2^{+11 R}$ & Sox $2^{1 / R / R}$ & \\
\hline P14 & 69 & 123 & 66 & \\
\hline Sox $2^{\text {+IKGFP }} \times$ Sox $2^{\text {+IIR }}$ & $+1+t$ & Sox $2^{+/ 1 R}$ & Sox $2^{+1 / 18}$ & Sox $2^{\text {EGFPगIIR }}$ \\
\hline embryonic & 85 & 70 & 72 & 73 \\
\hline P14 & 79 & 83 & 76 & 21 \\
\hline So $\times 2^{-+1 / P} \times \operatorname{Sox} 2^{+1 / T}$ & $+1+$ & Sox $2^{+1 . T}$ & Sox $2^{1 P T T P}$ & \\
\hline P14 & 48 & 76 & 47 & \\
\hline Sox $2^{\text {FEGTP }} \times$ Sox $2^{\text {TLLP }}$ & $+/ t$ & Sox $2^{+L L P}$ & Sox $2^{+/ E G T P}$ & Sox $2^{\mathrm{EGTTPLT}}$ \\
\hline embryonic & 129 & 105 & 104 & 103 \\
\hline P14 & 39 & 30 & 31 & 0 \\
\hline
\end{tabular}

Sox $2^{L P}$ and $\operatorname{Sox} 2^{I R}$ alleles effectively act as hypomorphic alleles, displaying $<40 \%$ activity in a Sox2-null genetic background; Sox2 mRNA (data not shown) and protein levels in cells isolated from embryonic day 14 (E14) CNS cortex (Fig. 3A,B) and eyes (Fig. 3C,D) are decreased to $15 \%-30 \%$ and $20 \%-40 \%$ of wild type in Sox $2^{E G F P / L P}$ and Sox $2^{E G F P / I R}$ mice, respectively.

Animals heterozygous for Sox $2^{+/ E G F P}$, Sox $2^{+/ C O N D}$, Sox2 $2^{+/ I R}$, and Sox2 $2^{+/ L P}$ and homozygous for Sox2 COND/COND, Sox $2^{I R / I R}$, and Sox $2^{L P / L P}$ are viable, born in appropriate Mendelian ratios, and are phenotypically and morphologically indistinguishable from wild-type mice (Fig. 2E; Supplementary Fig. 1). However, Sox2 hypomorphic/null compound heterozygotes (Sox $2^{E G F P / I R}$ and Sox $2^{E G F P / L P}$ ) display a range of eye phenotypes from mild bilateral microphthalmia to severe anophthalmia. Histological analyses of postnatal Sox $2^{E G F P / I R}$ mice show that the majority of mutant retinas are $\sim 30 \%-40 \%$ thinner than wild-type retinas. The thinning of the retina is associated with a reduction in cell number resulting in the decreased widths of the inner nuclear and plexiform layers (Fig. 3E,F). Additionally, a majority of mutant eyes display areas with disrupted cell layering, consisting of rosette structures (Fig. 3G; Fig. 6D-F [below]). By E14.5, eyes in embryos of both Sox2 hypomorphic/null compound heterozygotes (Sox2 $2^{E G F P / I R}$ and $\left.\operatorname{Sox} 2^{E G F P / L P}\right)$ are smaller than eyes of Sox2 heterozygous $\left(S_{S} 2^{+/ E G F P}\right)$ or wild-type littermates $\left(\right.$ Sox $2^{+/+}$) (Fig. 3H,I; Supplementary Fig. 1) and, consistent with a dose-dependent function for SOX2, complete ablation of SOX2 specifically in retinal progenitors $\left(\alpha P O-C R E\right.$; Sox $\left.2^{E G F P / \triangle C O N D}\right)$ correlates with a further reduction in eye size (Fig. 3J; see below).

\section{SOX2 is required for the proliferative and differentiation capacity of retinal progenitors}

To determine the requirement for SOX2 in retinal progenitor cells, we used a Cre-loxP strategy to conditionally inactivate Sox2 specifically in the mouse neural retina. In $\alpha$ P0-CREiresGFP mice, the expression of CRE and GFP is regulated by a retina-specific mouse Pax6 regulatory element such that CRE-recombinase activity is detected exclusively in the neural retina from E10.5 (Marquardt et al. 2001). Consistent with the general re- 
$A$

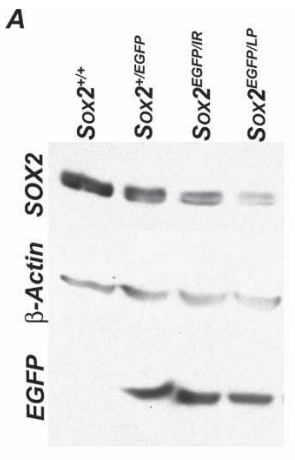

B

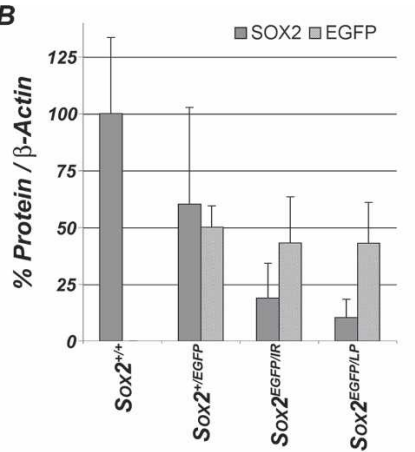

C
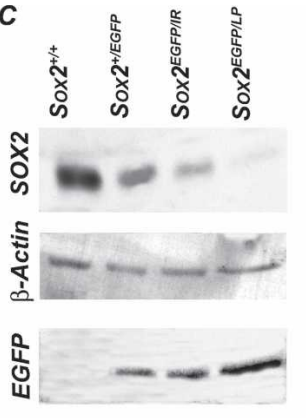

$D$

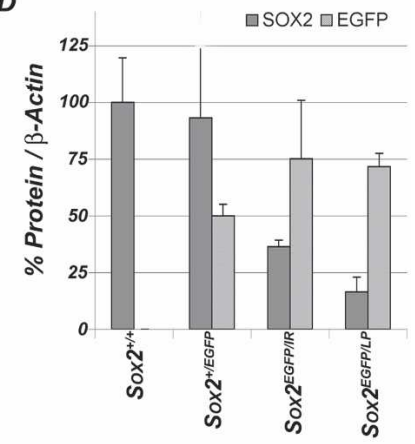

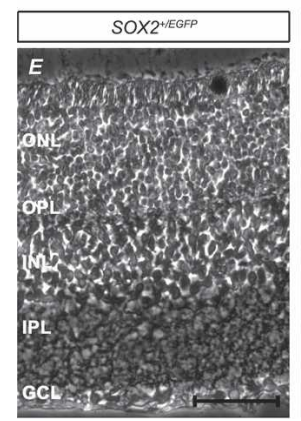
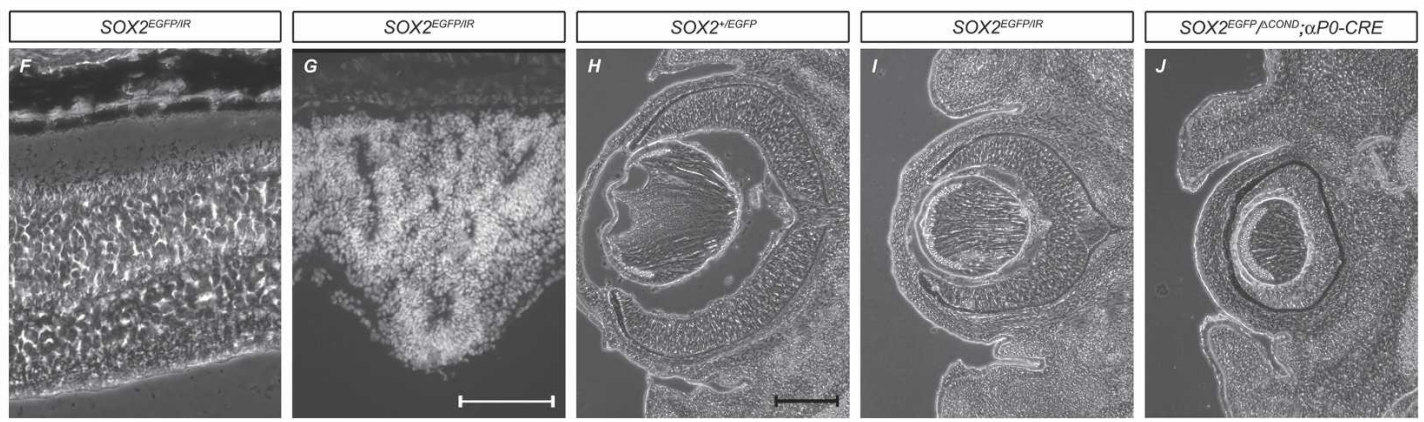

Figure 3. Analysis of $S o x 2^{I R}$ and Sox $2^{L P}$ hypomorphic alleles. $(A, C)$ Immunoblot of protein extracts from wild-type and Sox2 mutant embryos; E14.5 brains and eyes, respectively, were developed with antibodies against SOX2. $\beta$-ACTIN antibody was used as a loading quantity control and an antibody against EGFP was used to control for the amount of putative SOX2 expressing cells in the sample. Note that the expression level of EGFP from the Sox2 locus is preserved throughout. $(B, D)$ Quantification of the immunoblot results. SOX2 expression in Sox $2^{+/+}$was taken as baseline $(100 \%)$, and EGFP expression in Sox $2^{+/ E G F P}$ was designated as $50 \%$. $N=2$ for each genotype. (E-G) Compared with the Sox2 heterozygous mouse $\left(\operatorname{Sox} 2^{+/ E G F P} ; E\right)$, the compound null hypomorphic adult $\left(\right.$ Sox $\left.2^{E G F P / I R} ; F\right)$ shows a significant reduction in the thickness of the retina. By E14.5, the null hypomorph exhibits distinct rosette structures $\left(\right.$ Sox $\left.2^{E G F P / I R} ; G\right) .(H-J)$ Comparison of eye morphology of E14.5 Sox $2^{+/ E G F P}$, Sox $2^{E G F P / I R}$, and Sox $2^{E G F P / \triangle C O N D} ; \alpha P O-C R E$ mice. Bars: E,F, $50 \mu \mathrm{m} ; G, 100 \mu \mathrm{m} ; H-J, 200 \mu \mathrm{m}$.

striction of CRE expression to distal retinal progenitor

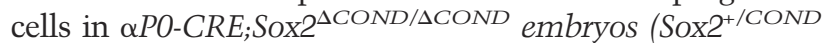
were crossed to Sox $2^{+/ E G F P} ; \alpha P O-C R E$ and Sox $2^{+/ \triangle C O N D}$; $\alpha P O-C R E$ ), SOX2 is eliminated from these cells (Fig. 4A,F and $B, G$, respectively).

A hallmark of SOX2-expressing neural progenitors is the maintenance of proliferative and differentiation capacity. It was shown previously that inhibition of SOX2 signaling by overexpression of a dominant interfering form of SOX2 in chick neural progenitors results in their premature exit from the cell cycle (Bylund et al. 2003; Graham et al. 2003). By E13.5, retinas of Sox $2^{\triangle C O N D / \triangle C O N D}$; $\alpha P 0-C R E$ embryos (Fig. $4 \mathrm{H}$ ) are significantly smaller in size compared with Sox2 $2^{+\triangle C O N D} ; \alpha P O-C R E$ retinas (Fig. 4C) as shown by PCNA staining. To further determine whether the hypocellular phenotype observed in Sox $2^{\triangle C O N D / \triangle C O N D} ; \alpha P O-C R E$ retinas is due to decreased proliferation, we assayed the expression of PCNA and incorporation of Bromodeoxy-Uridine (BrdU) into $S$ phase nuclei. Although PNCA (Fig. $4 \mathrm{H}$ ) remained expressed throughout the Sox $2^{\triangle C O N D / \triangle C O N D} ; \alpha P O-C R E$ retinas E13.5, there is a marked reduction of BrdU incorporation in cells of the distal retina of Sox $2^{+/ \triangle C O N D} ; \alpha P O$ $C R E$ embryos compared with cells of the central retina, thus indicating exit from cell cycle (Fig. 4I). In contrast,
BrdU labeling in control embryos $\left(\operatorname{Sox}^{+/ \Delta C O N D} ; \alpha P 0\right.$ $C R E)$ is evenly distributed throughout the distal-central retina (Fig. 4D). Furthermore, the DNA content of the distal retina (GFP positive) cells of wild-type $\left(\operatorname{Sox} 2^{+/ \triangle C O N D}\right.$; $\alpha P O-C R E)$ and mutant Sox $\left.2^{\triangle C O N D / \triangle C O N D} ; \alpha P O-C R E\right)$ mice was compared using flowcytometric cell cycle analysis. These data show that ablation of SOX2, specifically in the cells expressing $\alpha P O-C R E$, decreases the number of cycling cells (S/G2/M) from $31 \%$ to $8 \%$ (Supplementary Fig. 2). In addition to a decrease in BrdU incorporation and exit from cell cycle, Sox2 mutant distal RPCs, while maintaining expression of PCNA and PAX6, do not express molecular markers that define undifferentiated cycling RPCs such as Notch1 (Fig. 4E,J) and Hes-5 (Fig. 4K,P). Together these results demonstrate that SOX2 is required for appropriate neural retinal progenitor proliferation and maintenance of molecular markers that define progenitor identity.

To determine whether SOX2-null retinal cells that exit cell cycle differentiate into post-mitotic neurons, we assayed the expression of neuronal markers Math5, NeuroD, $\beta$ TUBULINIII (Fig. 4L-N,Q-S), and ISLET1 (data not shown). In distal regions of Sox $2^{\triangle C O N D / \triangle C O N D}$; $\alpha P O-C R E$ retinas, Math5, NeuroD, and $\beta$ TUBULINIII were absent (Fig. 4Q-S). Thus, complete genetic ablation 
Taranova et al.
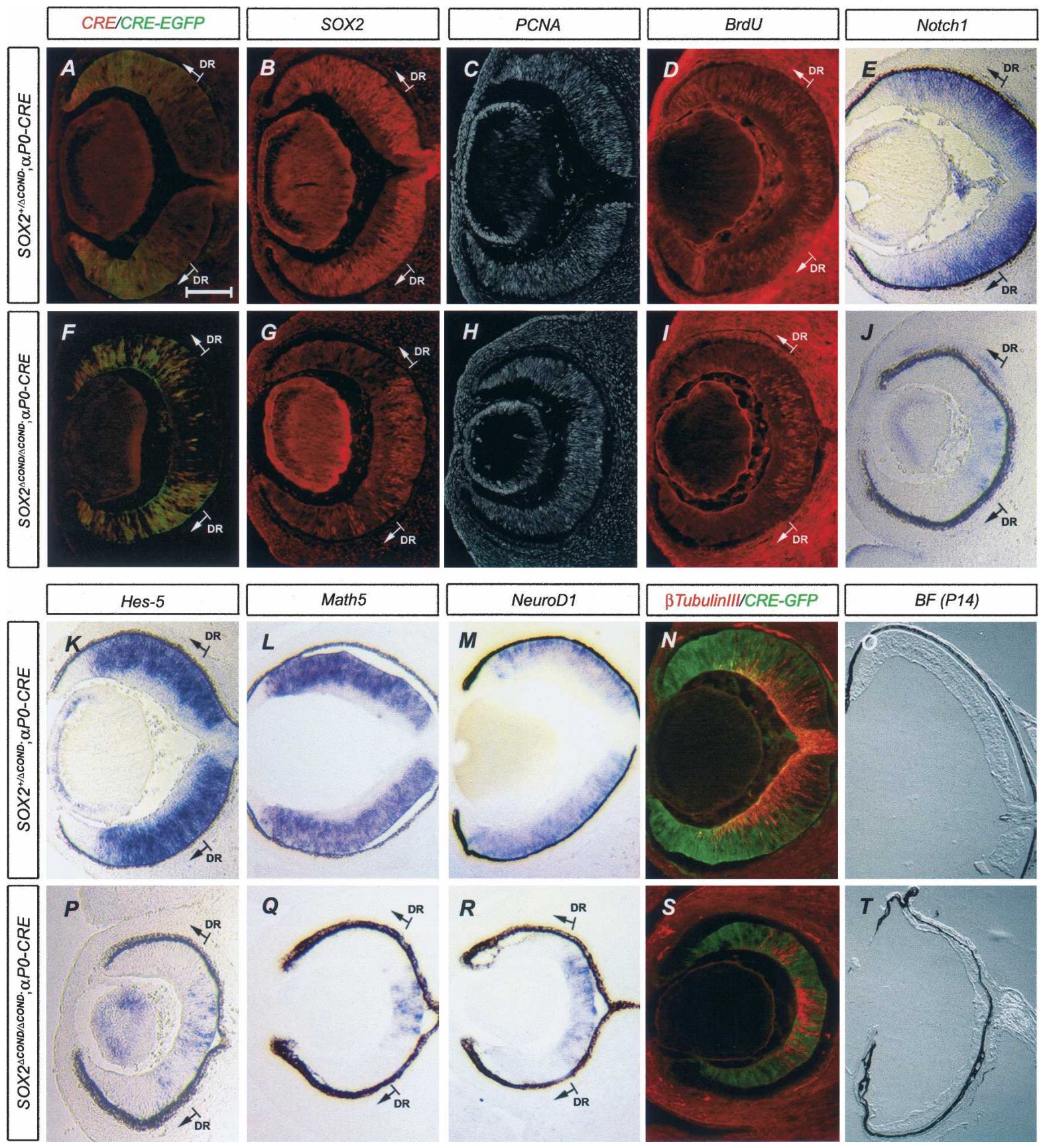

Figure 4. Ablation of SOX2 expression from neural progenitors inhibits their proliferation and differentiation. Sox2 conditional

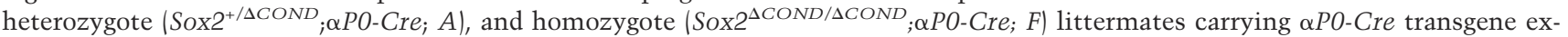
press CREiresGFP in distal retina (DR) at E13.5, as identified by antibody staining (red) and GFP expression (green). SOX2 expression is maintained in the DR of the SOX2 $2^{+/ E G F P} ; \alpha P O-C R E$ mouse $(B)$, while CRE-driven recombination eliminates SOX2 expression in the DR of the Sox $2^{\triangle C O N D / \triangle C O N D} ; \alpha P O-C r e$; embryo $(G)$. At E13.5, the loss of SOX2 expression in the neural progenitor cells of the DR results in an overall hypocellularity of the Sox $2^{\triangle C O N D / \triangle C O N D} ; \alpha P O-C r e(H)$, compared with the Sox ${ }^{+/ \Delta C O N D} ; \alpha P O-C r e(C)$. Compared with the $S_{0 x^{+} / \triangle C O N D} \alpha P O-C r e$, proliferation, progenitor marker expression and neuronal differentiation are obstructed in DR of Sox $2^{\triangle C O N D / \triangle C O N D} ; \alpha P 0$-Cre mice, as illustrated by the decreased incorporation of $\operatorname{BrdU}(D, I)$ and the absence of Notch1 (E,J), Hes-5 $(K, P)$, Math5 $(L, Q)$, NeuroD1 $(M, R)$, and $\beta$ TUBULINIII $(N, S)$ expression. By birth, the Sox2 $2^{\Delta C O N D / \triangle C O N D} ; \alpha P O-C r e$ retina is comprised of regions displaying varying degrees of cellular deterioration $(T)$ compared with $S o x 2^{+/ \triangle C O N D} ; \alpha P O-C r e$ retina $(O)$. Bars, $A-T, 100 \mu$ m.

of Sox2 results in the loss of general retinal progenitor cell characteristics: the ability to proliferate and appropriately differentiate. Consistent with previous reports
(Kammandel et al. 1999), we detected a variegated expression of the CREiresGFP transgene driven by the combination of the $\alpha$ enhancer and P0 promoter of 
mouse Pax6 gene within the distal retina. The observed variability was increased in Sox $2^{\triangle C O N D / \triangle C O N D} ; \alpha P O-C R E$ mice ranging from mosaic CREiresEGFP expression restricted to the distal retina to widespread CREiresGFP distribution throughout the circumference of the retina (Supplementary Fig. 3, cf. A and D). The coincident ablation of SOX2 with expression of CRE and the mutually exclusive expression of neuronal differentiation marker ( $\beta$ TUBULINIII; red) and CREiresGFP (green) in Sox $2^{\triangle C O N D / \triangle C O N D} ; \alpha P O-C R E$ embryonic retinas (Fig. $4 S$; Supplementary Fig. 3) indicates that SOX2 acts in a cell autonomous manner. A cell-autonomous role for SOX2 in retinal neural progenitor cells could explain the varying degrees of retinal cell loss in Sox $2^{\triangle C O N D / \triangle C O N D} ; \alpha P O$ $C R E$ (Fig. 4T) compared with Sox $2^{+/ \Delta C O N D} ; \alpha P O-C R E$ (Fig. 4O).

These results show that SOX2 plays a role in maintaining retinal neural progenitors in an undifferentiated proliferative state and, taken together with results from studies of SOX2 in the developing neural tube, imply a general requirement for SOX2 in neural progenitor cell populations.

\section{Eye morphogenesis in Sox2 hypomorphic mice}

The progressive increase in the severity of eye phenotypes displayed by mice carrying Sox2 mutant alleles (Fig. 3H-J) strongly suggests that the level of SOX2 is critical for normal retinal development. It is becoming recognized that the absolute level of a specific transcription factor is an important component of the mechanism of lineage specific regulation (Kulessa et al. 1995; DeKoter and Singh 2000; Motohashi et al. 2000, 2004; Emambokus et al. 2003). Moreover, it has been proposed that neural progenitor cell heterogeneity is triggered in part through a gene-dosage effect (Marquardt and Gruss 2002; Sinor and Lillien 2004).

To directly determine the functional significance of decreasing levels of SOX2 expression, we analyzed the phenotypic and molecular consequences in retinal neural progenitors of Sox2 hypomorphic/null mouse mutants $\left(S O x 2^{E G F P / I R}\right.$ and Sox $\left.2^{E G F P / L P}\right)$. Gross morphological analyses of Sox $2^{E G F P / I R}$ brains show hypoplasia of optic nerves and chiasmata (Fig. 5A,E). RGCs are the only retinal projection neurons to extend axons outside the eye; their axons grow laterally toward the presumptive optic nerve head and pass outward through the optic stalk to travel along the optic nerve to the chiasm. Thus, the observed failure to form optic nerves in Sox $2^{E G F P / I R}$ mice strongly suggests a defect in RGCs due to early disruption of SOX2.

To determine whether the Sox $2^{I R}$ mutation affects differentiation of retinal neurons, we used immunostaining to evaluate the differentiation of distinct cell types in postnatal Sox $2^{E G F P / I R}$ retinas. RGCs, as marked by NEUROFILAMENT (Fig. 5B,F, arrows), BRN3b (Fig. 5C,G, arrows), and ISLET1 (Fig. 5D,H, arrows) expression, are absent. On the other hand, markers of amacrine cells (CALRETININ, Fig. 5I,M, arrowheads), bipolar cells (PKC, Fig. 5J,N), rod photoreceptors (RHODOPSIN, Fig.
5K,O, arrowhead) and horizontal cells (NEUROFILAMENT, Fig. 5B,F, arrowhead) are expressed, and Müller glia are formed in Sox2 $2^{E G F P / I R}$ retinas (GFAP, Fig. 5L,P; CRABLP, Supplementary Fig. 4D,F). Interestingly, whereas GFAP expression in the wild-type and heterozygous $\left(\right.$ Sox $\left.2^{+/ G F P}\right)$ mouse retina is restricted to the distal region, the Sox $2^{E G F P / I R}$ retina expresses GFAP throughout the distal-central axis. Colabeling with CRABLP identified these cells as Müller glia (Supplementary Fig. 4), which in the central region of the wild-type mouse retina do not normally express GFAP. Therefore, the observed increase in GFAP expression in the Sox $2^{E G F P / I R}$ retina appears to be an up-regulation of GFAP in these cells and not an increase in their cell number. In addition to an apparent absence of RGCs, the majority of Sox $2^{E G F P / I R}$ eyes show disrupted cell layering, which is demonstrated by the presence of rosette structures (Figs. 3, 6 [cf. A-C and D-F]). The rosette structures are comprised of differentiated retinal neuronal subtypes. For example, they contain rod cells (marked by RHODOPSIN, Fig. 6C,F) surrounded by horizontal cells (marked by NEUROFILAMENT, Fig. 6B,E) and amacrine cells (marked by CALRETININ, Fig. 6A,D).

\section{Reduction in SOX2 levels restricts retinal neural progenitor competence}

To determine whether RGCs are generated during embryogenesis in Sox $2^{E G F P / I R}$ mice, we assessed Brn $3 \mathrm{~b}$ and $\beta T U B U L I N I I I$ expression, which at E15 identify differentiating RGCs. In both the wild-type and Sox $2^{E G F P / I R}$ mutant retina, Brn $3 b$ and $\beta$ TUBULINIII-positive cells could be identified in the inner side of the developing neural retina, consistent with the formation of RGCs (Fig. 6G,L,H,M). Although RGCs were present in the Sox $2^{E G F P / I R}$ mutant retina, the cells were inappropriately localized. For example, $\beta$ TUBULINIII-positive cells were not restricted to the inner side, but could also be detected in the outer RBL layer, which normally at this stage consists of undifferentiated progenitor cells (Fig. $6 \mathrm{M}$, arrows). These regions contained fewer progenitors, as marked by PCNA, and showed disruption of retinal laminar structure (Fig. 6I,N, arrow). Moreover, the RGC axons of Sox $2^{E G F P / I R}$ retinas, as marked by $\beta$ TUBULINIII (Fig. 6, cf. H and M) and anterograde labeling of retinal ganglion cells with Dextran-Cy3 (Fig. 6, cf. J and O, dotted outline), are scattered to subretinal spaces and fail to enter the optic nerve. This failure of SOX2 hypomorphic RGCs to reach their target is consistent with an increase in apoptotic cells as indicated by Caspase 3 staining (Fig. 6K,P).

Neural progenitor cells are characterized and defined by their pseudoepithelial morphology, proliferative capacity, and gene-expression profiles. The disruption in retinal structure and aberrant ganglion cell differentiation in Sox $2^{E G F P / I R}$ retinas indicates a change in progenitor properties due to a decrease in the level of SOX2. To address this question and begin to determine the molecular basis for these defects, we examined the expression of markers that define progenitor cells and the onset 

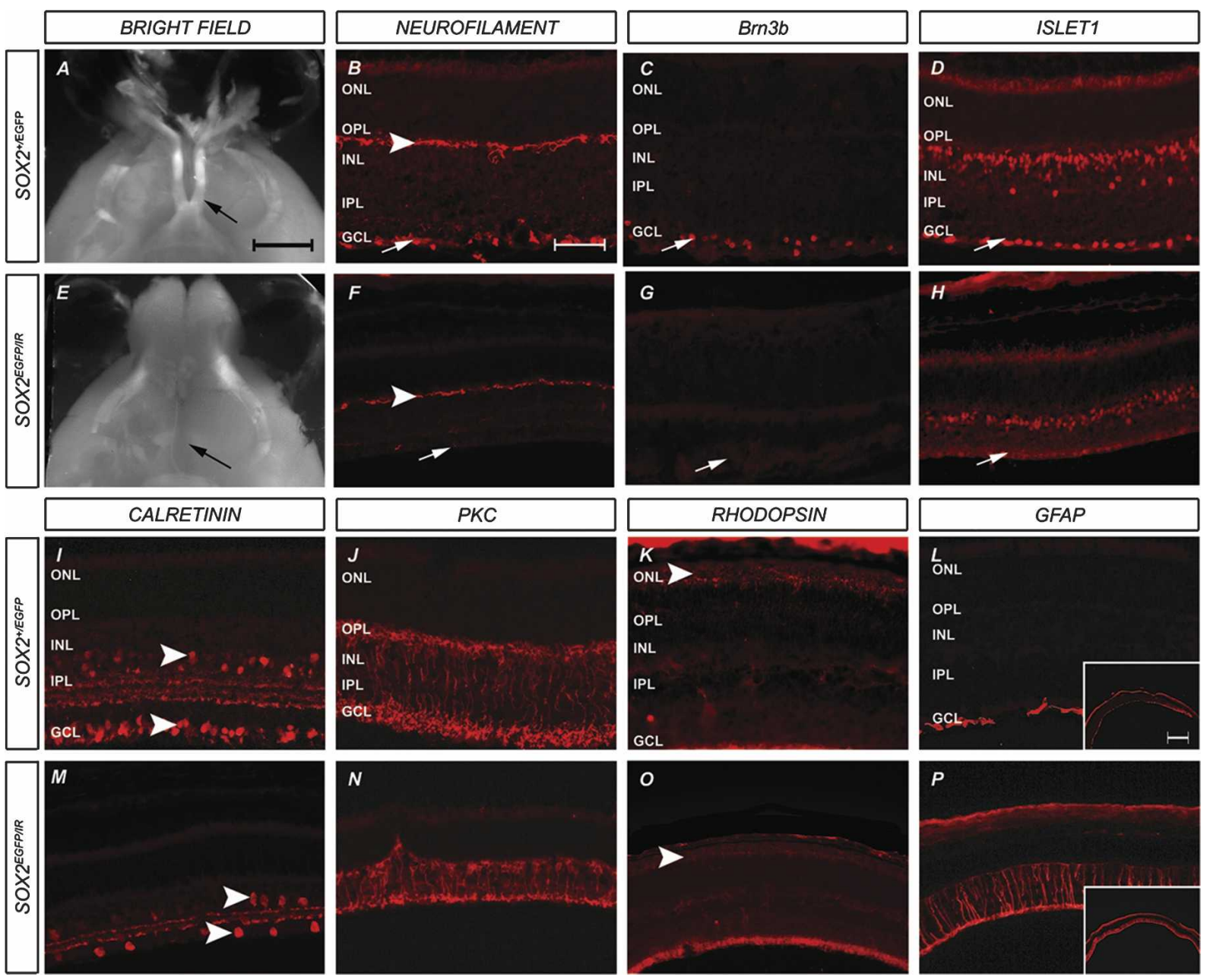

Figure 5. Decrease in SOX2 levels leads to hypoplasia of the optic nerve and loss of retinal ganglion cells. Ventral side of 3-mo-old Sox $2^{+/ E G F P}(A)$ and Sox $2^{E G F P / I R}(E)$ brains. $(E)$ Note the absence of developed optic nerve (arrow) in Sox $2^{E G F P / I R}$. Immunostained sections

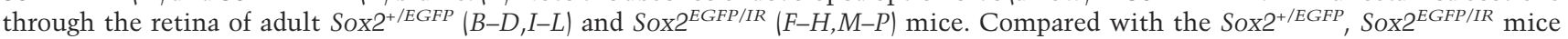
show $\sim 95 \%$ reduction in the number of cells immunostained for NEUROFILAMENT $(B, F$, arrows), Brn3b (C, $G$, arrows), and ISLET1 $(D, H$, arrows), and a $\sim 60 \%-70 \%$ reduction in cells stained with CALRETININ $(I, M$, arrowhead) in the ganglion cell layer (GCL). In contrast, interneurons demonstrate a relatively normal distribution, as shown by staining for NEUROFILAMENT $(B, F$, top arrowheads), ISLET1 $(D, H)$, CALRETININ $(I, M)$, and PKC $(J, N) .(I, M)$ Note the significant reduction in size of inner plexiform synaptic layer (IPL) as visualized by CALRETININ staining (arrowheads). (K,O) No cell loss was apparent in outer nuclear layer (ONL) formed by photoreceptor cell bodies, as confirmed by RHODOPSIN staining of the outer segments (arrowheads). (L, $P)$ We noted an up-regulation of GFAP expression in central retina of the SOx $2^{E G F P / I R}$ mice as compared with the Sox $2^{+/ E G F P}$ mice (insets, gross morphology). Bars: $A, E, 2 \mu \mathrm{m} ; B-D, F-P, 100 \mu \mathrm{m} ; L, P$ (insets), $200 \mu \mathrm{m}$.

of their differentiation in Sox $2^{E G F P / I R}$ mice, focusing on regulators of RGC differentiation. A number of transcription factors have been shown to serve as intrinsic regulators of RGC differentiation, among them the homeodomain factor PAX6 and basic helix-loop-helix (bHLH) factors MATH5, NEUROD, HES-1, and HES-5, GLI1 (Marquardt and Gruss 2002; Hatakeyama and Kageyama 2004; Mu et al. 2005). PAX6 is required for the activation of MATH5, an essential factor for RGC lineage specification. NEUROD1, another member of bHLH proneural genes, is also implicated in promoting retinal neuronal differentiation. In contrast, the NOTCH pathway negatively regulates RGC differentiation by activating the Hairy-enhancer of Split (HES) family of
bHLH genes, Hes-1 and Hes-5, thereby repressing the proneural bHLH factor Math5. Thus, the PAX6 and NOTCH pathways counter each other in the regulation of downstream genes required for the generation of the RGC lineage. To assess the pathways disrupted in Sox2 mutants, we therefore compared Math5, NeuroD1, Gli1, PAX6, Notch1, and Hes-5 expression between the wildtype and Sox2 hypomorphic/null mutant retina. At E14 in both wild-type and Sox2 $2^{E G P / I R}$ retinas, Math5, NeuroD, Gli1, and PAX6, are expressed at high levels in the retinal outer layer (Fig. 7, cf. A-C,G,D-F,J) consistent with progenitor cell differentiation and generation of RGCs. In contrast, expression of Notch1 and Hes-5 (Fig. 7, cf. H,I and K,L), which function to repress RGC dif- 


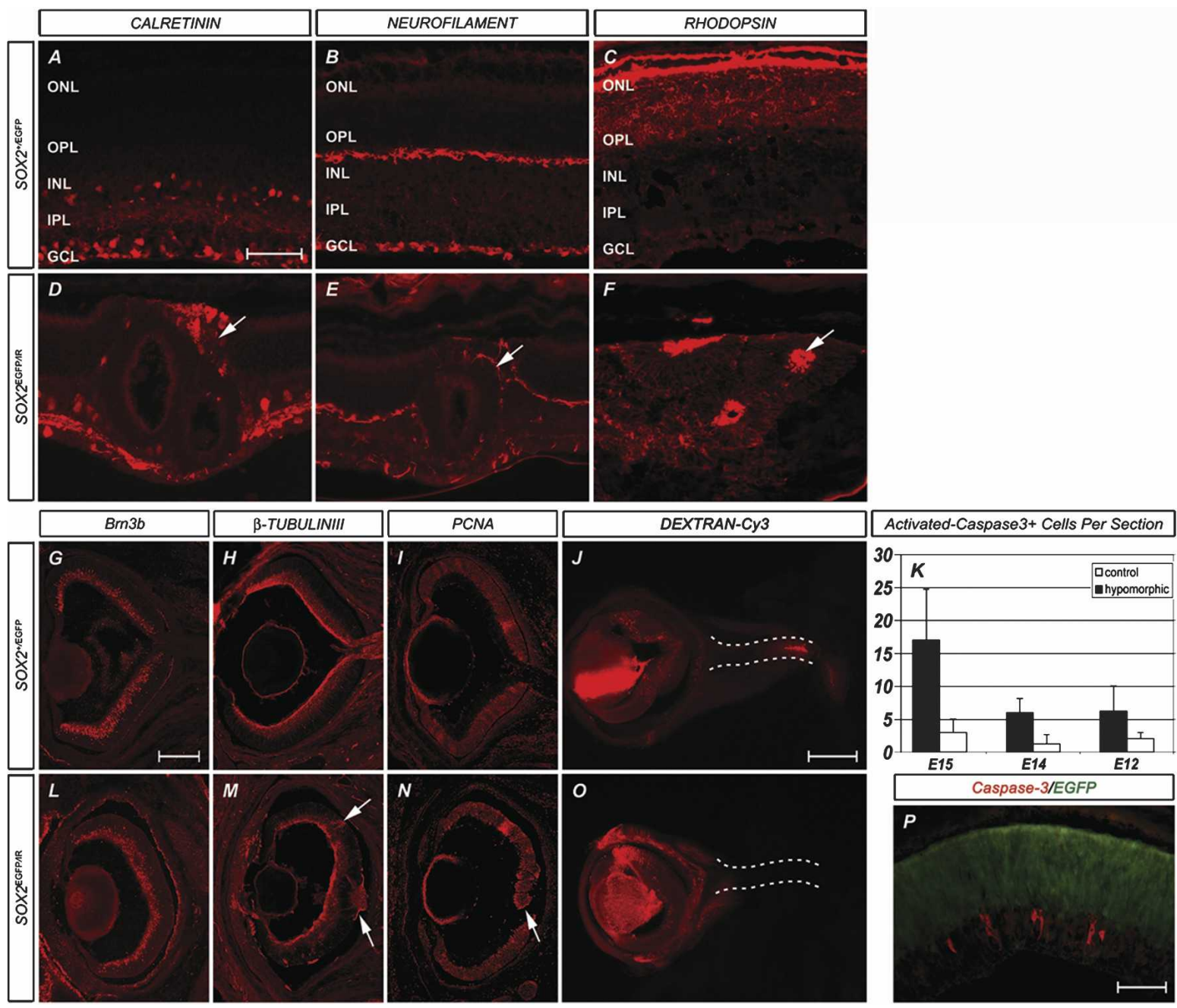

Figure 6. Reduction of SOX 2 expression disrupts retinal laminar morphology and impairs differentiation of RGCs. Immunostained sections through the retina of P20 Sox $2^{+/ E G F P}(A-C)$ and Sox $2^{E G F P / I R}(D-F)$ mice. Compared with the Sox2 $2^{+/ E G F P}(A-C)$, Sox2 ${ }^{E G F P / I R}$ $(D-F)$, mice show disruption of retinal cell layers with rosette structure formation. The rosette structures contain rod cells $(F$, RHODOPSIN, arrow) surrounded by horizontal cells ( $E$, NEUROFILAMENT, arrow) and amacrine cells ( $D$, CALRETININ, arrow). Representative horizontal sections of E15.5 $\operatorname{Sox}^{+/ E G F P}(G, H)$ and $\operatorname{Sox} 2^{E G F P / I R}(L, M)$ littermates immunostained for Brn3b and $\beta T$ UBULINIII. Both embryos show the presence of GCL; however, the differentiating neurites in the compound null hypomorphic retinas $(L, M)$ do not form a distinguishable fiber layer, and in the majority of cases fail to enter the optic nerve; $\beta$ TUBULINIII-positive cell bodies can be identified in the neuroblast layer $\left(M\right.$, arrow). Compared with $\operatorname{Sox} 2^{+/ E G F P}(I)$, these regions in $\operatorname{Sox} 2^{E G F P / I R}(N)$ retinas contain fewer progenitor cells as marked by PCNA staining. Anterograde labeling of the E14.5 retina with Cy3-dextran confirmed the loss of axonal projections from the retina in compound null hypomorphic retina ( $O$, dotted outline), compared with the Sox2 heterozygote (J, dotted outline). (K) Quantitative analysis of cells immunoreactive for activated CASPASE3. Cells were counted from horizontal section of E12, E14, and E15 mouse embryos; $n=4$ at each age. $(P)$ Representative section of E14 Sox2 ${ }^{E G F P / I R}$ retina illustrating CASPASE-3 staining in GCL. Bars, $A-F, 50 \mu \mathrm{m} ; G-I, L-N, 200 \mu \mathrm{m} ; J, D, 300 \mu \mathrm{m} ; P, 50 \mu \mathrm{m}$.

ferentiation and maintain progenitor identity, are significantly down-regulated in retinal progenitors of Sox2 hypomorphs. Wild-type levels of Notch1 and Hes-5 expression are maintained in the neural tube where SOX2 is coexpressed with SOX1 and SOX3, providing an internal control for in situ staining (Supplementary Fig. 5A-D). Furthermore, Western blot analyses of SOX2 and NOTCH1 expression in retinal cells isolated from wildtype, heterozygous, and hypomorphic/null Sox2 retinas indicate that the decrease in levels of SOX2 expression directly correlates with the decrease in levels of NOTCH1 expression (Supplementary Fig. 5E).
In SOX $2^{E G F P / I R}$ mutant retinas, down-regulation of SOX2 results in a decrease in the level of expression of NOTCH1 and its direct downstream target Hes-5, while expression of PAX6 and Math5 are up-regulated and Gli1 and NeuroD remain expressed. These data indicate that SOX2 may maintain retinal progenitor identity, at least in part, through the regulation of NOTCH1 signaling.

\section{SOX2 transcriptionally regulates Notch1 expression}

To establish whether Notch1 is directly regulated by SOX2, and to elucidate the molecular mechanisms un- 
Figure 7. Expression of molecular regulators of RGC differentiation in Sox2 hypomorphic mice. In situ hybridization on sections from E14 Sox2 $2^{+/ E G F P}(A-C, G-I)$ and SOx $2^{E G F P / I R}(D-F, J-L)$ embryos with probes for transcription factors involved in RGC differentiation. $(A, D)$ Math5. $(B, E)$ NeuroD1. $(C, F)$ Gli1. $(H, K)$ Notch1. Hes-5 $(I, L) .(G, J)$ Immunostaining for PAX6. Bars, $A-I, 200 \mu \mathrm{m}$.
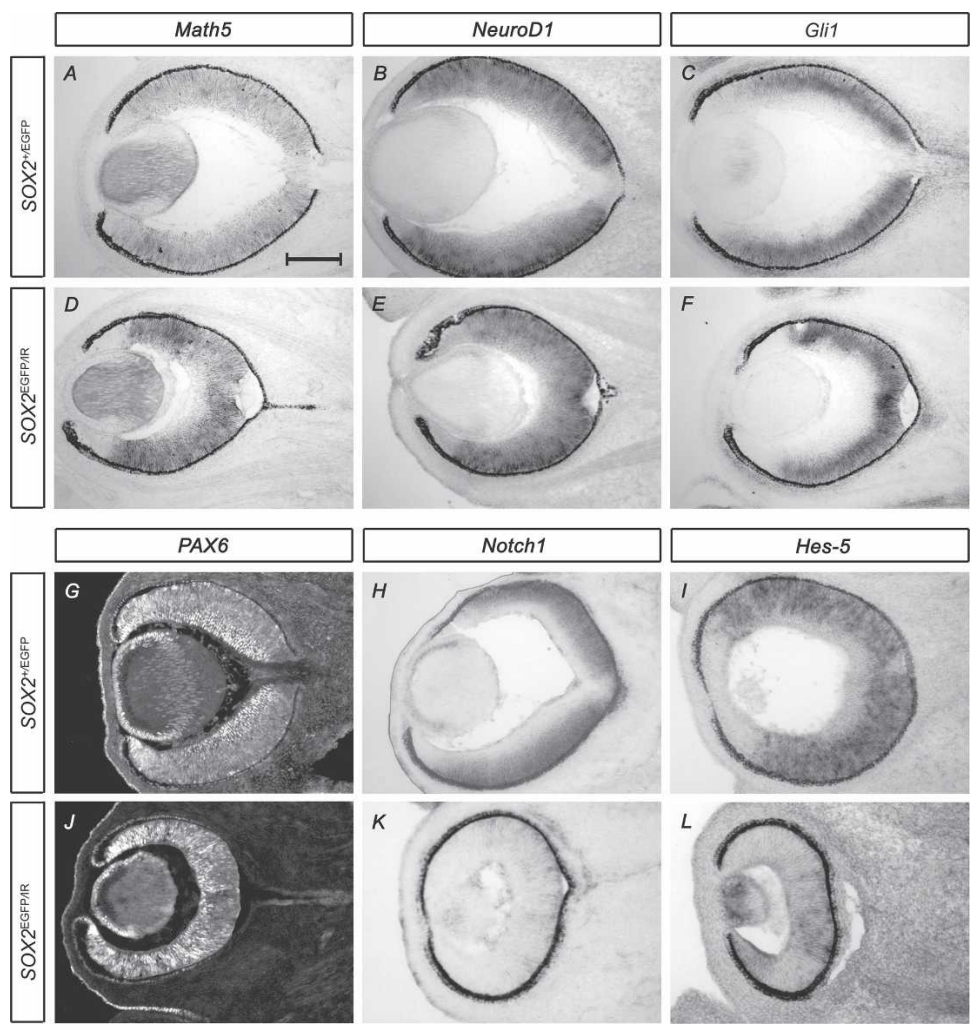

derlying SOX2 function, we conducted a chromatin immunoprecipitation (ChIP) cloning screen-a method that allows for the identification of direct downstream targets of a transcription factor (Weinmann et al. 2002). To this end, a library of ChIP DNA fragments was generated from embryonic stem (ES) cells using a SOX2 polyclonal antibody (Fig. 8A). Fifty clones were sequenced, and BLASTed against the whole mouse genome to identify the loci of the ChIP DNA fragments. Among the loci identified was Fgf4, a well-characterized direct target of SOX2 (Dailey et al. 1994). More critically we also identified a DNA fragment localized to intron 13 (IVS13) of the Notch1 locus (Fig. 8C).

To further validate the in situ binding of SOX2 to the IVS13 region of Notch1, and to demonstrate that the same SOX2-dependent enhancer of Notch1 could be ChIPed from CNS tissue, a ChIP PCR analysis (Fig. 8B) was conducted using mouse ES cells, E14.5 CNS tissue, and mouse embryonic fibroblasts (MEF, which lack SOX2), as a negative control. The results show that IVS13 of Notch1 is enriched upon ChIP in both ES cells and E14.5 CNS, but not in MEFs, or when using a nonspecific IgG antibody (Fig. 8C).

The 2.0-kb Notch1 IVS13 DNA fragment identified by ChIP was assessed for putative SOX2-binding sites. Bioinformatic analysis identified three SOX consensus sites within the 2.0-kb DNA fragment (Fig. 8D). To confirm SOX2 binding to the putative cis elements, DNase I footprinting analysis was conducted using a 150-base-pair (bp) probe that contained all three sites. Using HIStagged purified SOX2 protein, three strong DNase I in- terference patterns were observed, which directly correlate with the locations of the three SOX consensus sequences (Fig. 8E).

Furthermore, to determine whether the 150-bp fragment had the ability to enhance transcription, the Notch1 IVS13 fragment containing the SOX2 consensus sites was cloned into a minimal promoter luciferase reporter gene construct (Tugores et al. 1994) that was transiently transfected into the early ectodermal cell line P19 (Fig. 8F). The results show that the 150-bp Notch1 IVS13 DNA fragment increases transcription compared with the minimal promoter alone. Moreover, site-directed mutagenesis of the +26988 and +27001 SOX 2 cis elements ablates any enhanced transcription, indicating that the SOX2 consensus binding sites are critical for the transcriptional enhancement of the reporter gene construct. Together, these data strongly imply that Notch1 is transcriptionally regulated by SOX2.

\section{Discussion}

In this study we provide genetic evidence demonstrating that alterations in the levels of SOX 2 regulate the choice between maintenance of retinal progenitor cell identity and differentiation. Wild-type levels of SOX2 maintain progenitor developmental potency, the ability to proliferate and differentiate, while a decrease in SOX2 levels (<40\% of wild-type levels) results in the restriction of progenitor competence including the disruption of neuroepithelial morphology, proliferative capacity, and aberrant differentiation. In part, these characteristics of de- 
$\boldsymbol{A}$

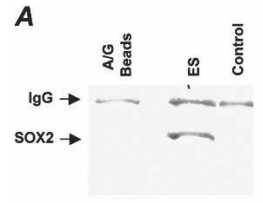

B

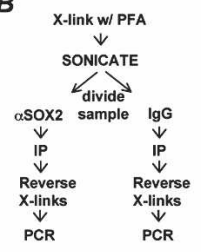

c

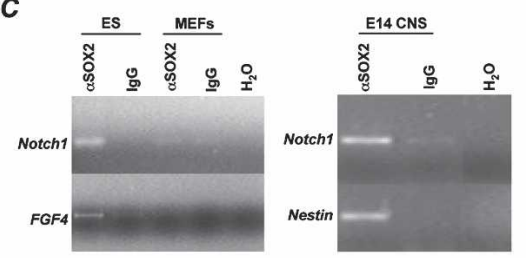

D

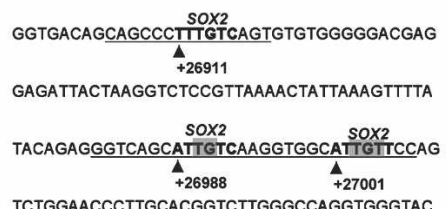

$F$
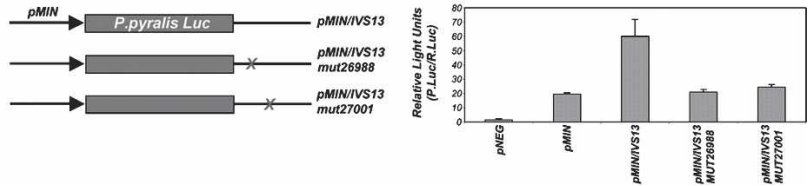

Figure 8. SOX2 binds IVS13 cis elements in the Notch1 gene. (A) Whole-cell extracts from ES cells and Control STO cells (which lack SOX2) were incubated with SOX2 antibody. SOX2 was efficiently immunoprecipitated (IPed) from only the ES cell extracts. (B) Schematic representation of standard ChIP PCR assay. PCR primers flanking the SOX2 consensus cis elements were used in a standard ChIP PCR assay with DNA template IPed from ES cells, E14.5 CNS, or MEFs as a control. Sonicated DNA was volumetrically divided in half to ensure equivalent input templates, and ChIP was conducted with either a SOX2 or nonspecific IgG as a control antibody. (C) The Notch1 IVS13 locus was IPed as a direct function of SOX2 binding in both ES cells and E14.5 CNS, but not from MEFs (which lack SOX2). Known SOX2 cis elements positioned in well-characterized enhancers of Fgf4 and Nestin were used as positive controls to demonstrate efficient ChIP using the SOX2 antibody. $(D)$ Probe sequence used for DNase I footprinting analysis. Numbers indicate the nucleotide positions of the SOX2 consensus sites within Notch1. The underlined sequence represents the area of the footprint pattern. Red boxes indicate bases in the SOX2 consensus sites that were mutated $1+26988$ : TG to CC, and +27001: TGT to GCA). (E) DNase I footprinting demonstrates the binding of proteins that produce interference patterns that localize specifically to SOX2 consensus sites within the Notch1 IVS13. Numbered arrows on the left indicate the location of the SOX 2 consensus sites in the probe. The schematic diagram on the right represents the approximate locations of SOX2 binding to the probe. (F, left schematic) Luciferase reporter gene constructs were generated that contained the intact 150-bp IVS13 DNA fragment or the same DNA fragment in which either the +26988 or +27001 SOX2 consensus sites were mutated. (Right graph) Transient transfections in P19 cells indicate that the 150bp IVS13 of Notch1 has the ability to enhance transcription of the reporter gene by approximately threefold, and that the +26988 and +27001 SOX2 consensus sites are required for transcriptional enhancement. fective retinal development in a Sox2-deficient genetic background are a consequence of altered NOTCH1 signaling. Our study shows a direct relationship between SOX2 and the Notch1 gene in that SOX2 interacts directly with a Notch1 enhancer, and that, in turn, the levels of SOX2 directly correlate with the levels of NOTCH1.

A role for SOX2 in vertebrate eye development was first suggested based on its expression pattern; SOX2 is expressed throughout the cells of optic vesicle of the anterior neural plate, transiently expressed in the newly induced lens, and is then restricted to proliferating progenitor cells of the neural retina (Kamachi et al. 1998; Van Raay et al. 2005). Consistent with its early expression in the anterior neural plate, inhibition of SOX2 signaling by injection of antisense morpholinos or dominant interfering forms of Sox2 into Xenopus embryos results, in addition to other morphological effects, in reduced or missing eyes (Mizuseki et al. 1998; Van Raay et al. 2005). Furthermore, misexpression of SOX2 in chick embryos has been shown to induce ectopic lens formation as marked by $\delta$-CRYSTALLIN (Kamachi et al. 2001). In order to bypass the early requirement of SOX2 in the anterior neural plate and to specifically address its role in neural retinal progenitor cells, we used the Cre-loxP strategy to conditionally inactivate Sox2 in the mouse. Our results demonstrate that SOX2 is required for the maintenance of neural retinal progenitor identity, such that after Cre-mediated ablation of SOX2 activity in the developing neuroretina, RPCs lose their ability to both divide and differentiate. Consequently, neurogenesis, including the up-regulation of bHLH factors (MATH5, NEUROD1) and the appearance of $\beta$ TUBULINIII differentiated neurons, was not observed in the Sox $2^{\triangle C O N D / \triangle C O N D}$; $\alpha P O-C R E$ mutant retinas. The cellular and molecular consequences of genetic ablation of Sox2 in progenitor cells of the neural retina in the mouse and the morpholino-knockdown of SOX2 in Xenopus further highlight an evolutionarily conserved function and requirement of SOX2 in retinal progenitor cell biology (Van Raay et al. 2005).

The complete genetic ablation of Sox2 described here in retinal neural progenitor cells phenocopies inhibition of SOX2 signaling in embryonic and adult neural tube progenitors. First, expression of a dominant interfering form of SOX2 in chick neural progenitors results in their premature exit from cell cycle (Bylund et al. 2003; Graham et al. 2003). Second, the conversion of rat oligodendrocyte precursors (OPCs) into multipotent neural stem cells (NSCL) is dependent on reinitiation of SOX2 expression, and inhibition of SOX2 signaling results in premature exit from cell cycle and neuronal differentiation of OPCs (Kondo and Raff 2004). Finally, it has recently been demonstrated that SOX2 expression is maintained in neurogenic regions of the adult rodent nervous system and that regulatory mutations of mouse Sox2 cause neurodegeneration and impair adult neurogenesis (Ferri et al. 2004). The conserved requirement for SOX2 in the CNS ventricular zone and retinal progenitors suggests that a common SOX2-regulated mechanism regulates the 
maintenance of progenitor cell identity in distinct regions of the CNS.

Despite mounting evidence that SOX2 is important in the maintenance of progenitor cell identity (Bylund et al. 2003; Graham et al. 2003; Ferri et al. 2004), the question remains: Does SOX2 interact with other genetic pathways implicated in this process, and if so, how? The maintenance of CNS progenitor identity is critically dependent on NOTCH signaling. NOTCH1, along with its two direct downstream targets HES-1 and HES-5, is coexpressed in the ventricular zone of the developing central nervous system including the retina, and maintains RPCs in an uncommitted state (Hatakeyama and Kageyama 2004; Hatakeyama et al. 2004). Moreover, the transition from uncommitted to lineage-restricted RPCs is coupled with both the down-regulation of NOTCH1 activity, presumably in response to extrinsic signals, and the activation of retinogenic bHLH factors such as MATH5, NEUROD1, and NGNs. However, what triggers the transition from an "uncommitted RPC" to a "lineage-restricted RPC" still remains unclear; for example, what intrinsic differences occur in RPCs when challenged with the same extrinsic signals?

Restriction of neural progenitor cell capacity is directly coupled with the down-regulation of SOX2 expression. Heterogeneity in SOX2 levels among progenitors could therefore allow cells to respond differently to the same extrinsic signals. By generating an allelic series of Sox2 to directly analyze the effects of graded reduction of SOX2, we provide genetic evidence that one of the intrinsic differences in progenitor cells is the level of SOX2, which may act by modulating NOTCH1 expression in neural progenitors. We present three independent sets of experiments demonstrating that Notch1 transcription is regulated by SOX2; an unbiased ChIP screen identified Notch1 as a direct target of SOX2 in vivo, DNase footprinting and Luciferase reporter assays showed that SOX2 can bind to Notch1 regulatory regions and regulate the levels of NOTCH1 expression in vitro, and finally, both NOTCH1 and its target Hes-5 are dramatically down-regulated in the retinas of Sox2 hypomorphic mice. Furthermore, ablation of NOTCH1 gives a retinal phenotype similar to that which we describe for Sox2-null mice (i.e., loss of RPCs) (Austin et al. 1995; Waid and McLoon 1995; Ahmad et al. 1997; Henrique et al. 1997; Jadhav et al. 2006), and the retinal phenotypes of both Hes-1 and Hes-5 mutant mice are strikingly similar to the phenotype observed in Sox2-hypomorphic mice, in that RPCs aberrantly differentiate and abnormal "rosette-like" structures are present (Ishibashi et al. 1994; Tomita et al. 1996). The lack of balance between lateral inhibitory signaling by NOTCH1 and proneural gene products results in differentiation of RPCs-a mechanism that may extend to other CNS progenitors. The data presented in this study provide a molecular explanation for the inverse correlation between the levels of proneural bHLH and SOXB1 factor expression in chick spinal-cord progenitor cells in that the capacity of proneural bHLH proteins to direct neuronal differentiation crucially depends on the suppression of SOX1,
SOX2, and SOX3 (Bylund et al. 2003). In light of the conserved expression/function of NOTCH1 signaling in other stem cell/progenitor populations, and the ability of other SOX proteins to bind the loose SOX consensus sequence, other SOX family members may act in a similar manner to universally conserve the "stemness" identity. Consistent with this, SOX10 has been implicated to act in a dosage-dependent manner in the peripheral nervous system to maintain neural crest stem cell identity by indirectly regulating the expression of bHLH factors (Kim et al. 2003).

Our data show that cell fate determination of retinal progenitor cells is dependent on the levels of SOX2; however, the molecular mechanism by which SOX2 dosage regulates cell fate remains to be elucidated. To date, two major mechanisms of transcriptional regulation by SOX factors have been suggested; protein-protein interaction and modification of chromatin structure (Pevny and Lovell-Badge 1997; Kamachi et al. 1999). The expression of FGF4 and NESTIN, both previously identified as direct transcriptional targets of SOX2, is dependent on heterodimerization of SOX2 with protein partners, OCT3/4 and Brn2, respectively (Tanaka et al. 2004). In the context of an interacting protein network, it is possible that subtle differences in protein levels are sufficient to shift the equilibrium toward another transcription complex. Furthermore, binding of SOX factors, including SOX2, change the local conformation of DNA; i.e., introducing or stabilizing bends that may determine the accessibility of DNA to other transcription complexes (Scaffidi and Bianchi 2001). It is tempting to speculate that transcriptional networks, such as those including SOX factors, are highly sensitive to a dosage effect that can modify their capacity to form particular protein-protein interactions and/or affect changes in higher order chromatin structures. Precedent for this comes from studies of mechanisms regulating hematopoietic stem cell differentiation. For example, a gradient of the E2A transcription factor has been shown to determine the choice between stem, B- or T-cell fate. Moreover, based on NOTCH1 signaling studies, a reduction in $\mathrm{E} 2 \mathrm{~A}$ function in the common lymphoid precursor is permissive for T-cell lineage but not for the B-cell lineage that requires intact E2A activity (Zhuang et al. 2004).

The critical importance of precise regulation of transcription-factor dosage is further reinforced by the genetics of human syndromes. Humans with mutations in SOX2 display a spectrum of severe eye malformations ranging from unilateral microphthalmia to bilateral anophthalmia including, in some cases, aplasia of the optic nerve, chiasm, and optic tract. The severity of the disease state most likely reflects genetic variations within the human population, or alternatively, reflects the strength of the SOX2 mutation (e.g., null vs. hypomorphic). Detailed analyses of the cellular defects and molecular pathways associated with human SOX2-related retinal defects have been difficult to assess in patients, since the onset of the defect is developmental. Therefore, a viable approach to circumvent this problem is to generate a mouse model in which the earliest phenotypic 
sequelae of aberrant SOX2 expression can be monitored and studied in the embryo. Our analyses of an allelic series of Sox2 mutations in the mouse have confirmed a critical relationship between gene dosage of Sox2 and the severity of eye malformations. Micropthalmic and optic nerve hypoplasia was observed in Sox $2^{C O N D / C O N D} ; \alpha P O$ $C R E$ animals, thus implicating the disruption of SOX2 function specifically in the neural retina as a contributing factor to the phenotype observed in human SOX2Anophthalmia. Compound hypomorphic null mice $\left(\right.$ Sox $2^{E G F P / L P}$, Sox $\left.2^{E G F P / I R}\right)$ display a series of eye malformations, and in most severe cases, both eyes fail to develop (bilateral anophthalmia). Moreover, we have demonstrated that these differences in the severity of eye phenotypes correlate with the defects in the neural retina, and they are directly related to the levels of SOX2 expression. Although the phenotype observed in Sox2hypomorphic mice (compound heterozygotes) closely mimics that displayed in humans with SOX2 mutations, the defect in humans is primarily defined as a heterozygous disorder where one allele possesses a missense or null mutation, and the other allele is "wild type." Although we cannot rule out that species differences may account for a phenotypic difference between mouse and human, an intriguing point of speculation based on the genetic consequences of the Sox2-hypomorphic mouse is that humans with SOX2-related retinal defects may indeed be compound heterozygotes; that is, they may possess a null allele and a "low-expressing" allele that brings the total functional level of SOX2 to phenotypic levels $(<40 \%$ of normal). The literature is replete with examples of human disorders in which a low-expressing allele, combined with a null-allele, precipitates the disease condition. The molecular defects associated with a "low-expressing allele" range from enhancer defects to aberrant splicing and mRNA stability. Our study may shed light on potential regulatory mutations in the "unexplored" allele from cohorts already identified to possess a null-SOX2 allele. An alternative hypothesis is that humans with SOX2-related eye disorders have epistatic mutations or complex genetic interactions that result in retinal and/or lens defects. The Sox $2^{E G F P}$ and Sox2-hypomorphic mice provide critical genetic tools to identify interacting pathways necessary for normal eye development and causative to pathologic conditions.

\section{Materials and methods}

\section{Gene targeting and mouse breeding}

The Sox $2^{C O N D}$ targeting construct was generated by inserting a $\operatorname{lox} P$ site in the SpeI site $5^{\prime}$ of the first Sox2 exon and a PGK-Neo cassette flanked by a $\operatorname{lox} P$ site in the NheI site immediately $3^{\prime}$ to the Sox2 coding region (Avilion et al. 2003). The Sox $2^{L P}$ targeting construct was created by partial incorporation of the Sox $2^{\text {COND }}$ targeting vector into Sox2 locus. This introduced the $P G K-N e o$ cassette with a single loxP site into the first NheI site $3^{\prime}$ of Sox2 coding sequence (Fig. 2A). In the Sox $2^{I R}$ construct, the 3'UTR of Sox2 mRNA (EcoRV-NheI fragment) was replaced with IRESdsRed2 (Clontech) and loxP-flanked PGK-Neo cassette (Fig. 2C). Targeted constructs were electroporated into
CCE ES cells (gift from E. Robertson, Oxford University, Oxford, UK) and recombinants were identified using standard Southern blot analysis with $\alpha \mathrm{P}^{32} \mathrm{dCTP}$ DNA probes (Fig. 2B,D). Chimeric founder mice that transmitted the targeted alleles were produced by blastocyst injection. Sox $2^{\triangle C O N D}$ mice were generated by mating heterozygous Sox $2^{\text {COND }}$ mice to ACTBCre FVB/N-Tg(ACTB-cre)2Mrt/J, in which CRE recombinase is expressed in the female germline (Jackson Laboratories) (Lewandoski et al. 1997) and $\alpha \mathrm{P0}$-Cre mouse line (gift from Dr. P. Gruss, Max-Planck-Institute of Biophysical Chemistry, Germany) (Marquardt et al. 2001). PCR genotyping of Sox2 alleles was performed using the following sets of primers: for the wildtype allele $\left(\mathrm{Sox}^{+}\right) 5^{\prime}$-GCTCTGTTATTGGAATCAGGCTGC $3^{\prime}$ and $5^{\prime}$-CTGCTCAGGGAAGGAGGGG-3' primers; 35 cycles at $94^{\circ} \mathrm{C}$ for $15 \mathrm{sec}$, at $55^{\circ} \mathrm{C}$ for $30 \mathrm{sec}$, at $72^{\circ} \mathrm{C}$ for $30 \mathrm{sec}$; generated 382-bp product; for targeted alleles (Sox $2^{C O N D}$, Sox $2^{L P}$ and $\left.S_{0 \times 2} 2^{I R}\right) 5^{\prime}$-CAGCAGCCTCTGTTCCACATACAC-3' and $5^{\prime}$-CAACGCATTTCAGTTCCCCG-3' primers; 35 cycles at $94^{\circ} \mathrm{C}$ for $15 \mathrm{sec}$, at $56^{\circ} \mathrm{C}$ for $30 \mathrm{sec}$, at $72^{\circ} \mathrm{C}$ for $40 \mathrm{sec}$; generated 297 -bp product. The Sox $2^{\text {COND }}$ allele was detected using $5^{\prime}$ CTTCTTTCCGTTGATGCTTTCG-3' and $5^{\prime}$-ATCTTGGTG GCTGAACAGTTATCC-3' primers; 35 cycles at $94^{\circ} \mathrm{C}$ for 15 sec, at $55^{\circ} \mathrm{C}$ for $30 \mathrm{sec}$, at $72^{\circ} \mathrm{C}$ for $40 \mathrm{sec}$; by 589 -bp product. Sox $2^{E G F P}$ allele (Ellis et al. 2004) was genotyped using $5^{\prime}$ CGCTTCCTCGTGCTTTACG-3' and 5'-GGCTTCTCCTTT TTTTGCAGT- $3^{\prime}$ primers; 35 cycles at $94^{\circ} \mathrm{C}$ for $15 \mathrm{sec}$, at $60^{\circ} \mathrm{C}$ for $30 \mathrm{sec}$, at $72^{\circ} \mathrm{C}$ for $45 \mathrm{sec}$; by 750 -bp product.

\section{Northern blot analysis}

Total RNA was extracted from E14 mouse brains using Trizol reagent (Invitrogen) and analyzed by Northern blotting using $\alpha \mathrm{P}^{32} \mathrm{dCTP}$ DNA probes for Sox2 (PS2, Fig. 2A) and $\beta$-Actin (939bp fragment generated using 5'-GTGACGAGGCCCAGAG CAAGAG-3' and 5'-AGGGGCCGGACTCATCGTA-3' primers). The blots were developed using a PhosphorImaging Typhoon scanner (Amersham Biosciences) and quantified using ImageQuant (Amersham Biosciences).

\section{Immunoblotting}

Protein extracts were prepared from E14 embryonic brains or eyes in RIPA buffer (Magness et al. 1998) containing protease inhibitor cocktail (Sigma). Immunoblotting was conducted according to standard protocol using primary antibodies against SOX2 (Chemicon; 1:1000), EGFP (Molecular Probes; 1:5000), NOTCH1 (Santa Cruz Biotechnology; 1:1000) and $\beta A C T I N$ (Sigma; 1:5000). IgG-horseradish conjugate (Bio-Rad) was applied as the secondary antibody $(1: 10,000)$ and Enhanced Chemiluminescence Reagent (Amersham) was used for detection. Bands were quantified by scanning the film and the image densities analysis using NIH Image software (http://rsb.info.nih. gov/nih-image/Default.html).

Tissue preparation, immunohistochemistry, and in situ hybridization

Mouse embryos were fixed with $4 \%$ paraformaldehyde (PFA) in phosphate-buffered saline (PBS). Adult mice were perfused with $4 \%$ PFA and the eyes and brains were post-fixed for $30 \mathrm{~min}$ at room temperature. Tissue was immersed sequentially in $10 \%$, $20 \%$, and $30 \%$ sucrose/PBS and then embedded and frozen in OCT medium (Tissue-Tek). For BrdU labeling, pregnant mice were injected intraperitoneally with BrdU (100 mg per kilogram of body mass) and euthanized $2 \mathrm{~h}$ thereafter. Horizontal 12-14 $\mu \mathrm{m}$ cryostat sections were blocked in $1 \%$ goat serum in PBS/ 
$0.1 \%$ Triton-X 100 and incubated with primary antibodies at $4^{\circ} \mathrm{C}$ overnight and with secondary antibodies for $20 \mathrm{~min}$ at room temperature. Working dilutions and sources of the following antibodies were used in this study: SOX2 (Chemicon; 1:2000), SOX1 (Pevny et al. 1998) (1:500), PCNA (Biosource International; 1:500), BrdU (Becton Dickinson; 1:100), $\beta T U B U L I N I I$ (Covance; 1:1000), NEUROFILAMENT (Hybridoma Bank; 1:5000), CRALBP (1:4000), GFAP (DAKO; 1:500), PAX6 (Hybridoma Bank; 1:50), PAX6 (Covance; 1:200), ISLET1 (Hybridoma Bank; 1:50), CALRETININ (Chemicon; 1:1000), Protein Kinase $\mathrm{C} \alpha$ (Sigma; 1:1000), RHODOPSIN (Leinco Technologies; 1:50), Cre-recombinase (Novagene; 1:2000), activated CASPASE3 (Cell Signaling Technology; 1:50), Cy3-anti-mouse (Sigma; 1:200), Cy3-anti-rabbit (Sigma; 1:200). In situ hybridization was performed on 20 - $\mu$ m horizontal cryostat sections using DIGlabeled antisense RNA probes and followed by enzymatic detection according to manufacture protocols (Roche). The following probes were used: Math5 (Yang et al. 2003), NeuroD1 (Lee et al. 1995), Notch1 (Lardelli and Lendahl 1993), and Hes-5 (Chenn and Walsh 2002).

\section{ChIP library and PCR analysis}

A SOX2 ES ChIP library was generated essentially as described in Weinmann and Farnham (2002). Anti-SOX2 antibody (Chemicon; $2.5 \mu \mathrm{g} / \mathrm{mL}$ ) was used for IP with Protein A/G Agarose Plus (Santa Cruz Biotechnology) beads. ChIP material (1-4 ul) was used in a Zero-blunt TOPO cloning reaction (Invitrogen) and ChIP DNA fragments were sequenced. ChIP PCR analysis from isolated ES, MEF, and E14 mouse CNS cells was conducted using the gene-specific oligonucleotides Notch1, 5'-GTACC CACCTGGCCCAAGA- ${ }^{\prime}$ ' and 5'-GGTGACAGCAGCCCTTT GTC-3'; Nestin, 5'-CTGAGAATTCCCACTTCCCCT-3' and 5'-CCTCAGATCAGTCTCCGCCTC-3'; FGF4, 5' -CCAAAAT GGAAGAGCAGGGTC- $3^{\prime}$ and $5^{\prime}$-GCACCTAAGGAGTGGG CGTG- $3^{\prime}$; at $94^{\circ} \mathrm{C}$ for $15 \mathrm{sec}$, at $59^{\circ} \mathrm{C}$ for $10 \mathrm{sec}$, and at $72^{\circ} \mathrm{C}$ for $45 \mathrm{sec}$; for $32-35$ cycles to maintain PCR in linear range.

\section{Footprinting protection assay}

Full-length HIS-tagged SOX2 (pcDNA3.1- SOX2-V5HIS) was transiently expressed in 293 cells, purified with Ni-NTA beads according to manufacturer's protocol (Qiagen), and dialyzed against Dignam C with $50 \mathrm{mM} \mathrm{NaCl}$. Purification was assessed by Coomassie-stained SDS-PAGE gels and immunoblotting. A footprinting assay was conducted essentially as described (Tugores et al. 1994) using $30 \mu \mathrm{g}$ of purified SOX2-V5-HIS, dGdC, and a probe generated from the 150-bp amplicon recovered by PCR using the Notch1 primers described above.

\section{Luciferase assay}

The 150-bp DNA fragment (IVS13) used in the DNase I footprinting assay was cloned into the $3^{\prime}$ polylinker of p21LUC, which contains a minimal promoter driving expression of Photinus pyralis luciferase. Site-directed mutagenesis was carried out on the SOX 2 consensus sites, +26988 and +27001 , located in the 150-bp Notch1 IVS13 DNA fragment. The mutations were induced with the PCR primers +26988FOR (5'-CAGAGGGT CAGCATCCTCAAGGTGGCATTG-3' and the complementary primer) or +27001FOR (5'-CATTGTCAAGGTGGCAT GCATCCAGTCTGGAACCCTTG-3' and the complementary primer) using a modified QuickChange method (Stratagene). The +26988 site was converted from ATTGTC to ATCCTC and the +27001 site was converted from ATTGTT to ATGCAT. Notch1 IVS13 luciferase reporter gene constructs $(1 \mu \mathrm{gg} / 40$ wells), and CMV-Renilla luciferase $(0.2 \mu \mathrm{g} /$ well $)$ as a normalization control, were transiently transfected into the P19 cell line using Lipofectamine Plus reagent (Invitrogen) in OptiMEM medium (Gibco). After $12 \mathrm{~h}$ of exposure to transfection medium, the medium was replaced with DMEM-H (Gibco) supplemented with standard concentrations of glutamine, penicillin, and streptomycin, and incubated for an additional $36 \mathrm{~h}$. Forty-eight hours after transfection, the expression of both $P$. pyralis and Renilla Luciferase were assessed using the Dual Luciferase Reporter Assay System (Promega). All experiments were carried out in duplicate, and the transfection efficiency of Notch1 IVS13 reporter genes was normalized to CMV-Renilla luciferase activity.

\section{Fluorescence-activated cell sorting (FACS)}

Retinas from E13.5 wild-type (Sox2 $\left.{ }^{+/ \triangle C O N D} ; \alpha P O-C R E\right)$ and mutant $\left(S_{0 \times 2} 2^{\triangle C O N D / \triangle C O N D} ; \alpha P O-C R E\right)$ dissociated as described in Polleux and Ghosh (2002). Live cells $\left(10^{6}\right)$ were stained for 30 min at $37^{\circ} \mathrm{C}$ with Vibrant Violet dye (Invitrogen) and then subjected to FAC analysis using a CyAn flowcytometer (DAKO Cytomation, Glostrup). DNA content was determined specifically in $\alpha$ P0-CREiresGFP cells by gating on EGFP-positive cells and assessing Vybrant Violet fluorescence. DNA Content histograms were modeled for cell cycle parameters in 30,000 cells using MODFIT software (Verity).

\section{Acknowledgments}

We thank Dr. Peter Gruss for kindly providing $\alpha$ PO-CRE mice. We also thank Dr. W. Snider, Dr. A. LaMantia, and Dr. F. Conlon for critically reading the manuscript. Work in the L.P. laboratory is supported by NIH (NIMH) 64798-01 and in the UNC In Situ Core by NIH (NINDS) P30-S045892-02. S.M. is a recipient of a Christopher Reeves Paralysis Foundation post-doctoral fellowship. All animal work was carried out in accordance with University of North Carolina IACUC and DLAM approval.

\section{References}

Ahmad, I., Dooley, C.M., and Polk, D.L. 1997. Delta-1 is a regulator of neurogenesis in the vertebrate retina. Dev. Biol. 185: 92-103.

Austin, C.P., Feldman, D.E., Ida Jr., J.A., and Cepko, C.L. 1995. Vertebrate retinal ganglion cells are selected from competent progenitors by the action of Notch. Development 121: 3637-3650.

Avilion, A.A., Nicolis, S.K., Pevny, L.H., Perez, L., Vivian, N., and Lovell-Badge, R. 2003. Multipotent cell lineages in early mouse development depend on SOX2 function. Genes \& Dev. 17: 126-140.

Blackshaw, S., Harpavat, S., Trimarchi, J., Cai, L., Huang, H., Kuo, W.P., Weber, G., Lee, K., Fraioli, R.E., Cho, S.H., et al 2004. Genomic analysis of mouse retinal development. PLoS Biol. 2: E247.

Bylund, M., Andersson, E., Novitch, B.G., and Muhr, J. 2003. Vertebrate neurogenesis is counteracted by Sox1-3 activity. Nat. Neurosci. 6: 1162-1168.

Cepko, C.L., Austin, C.P., Yang, X., Alexiades, M., and Ezzeddine, D. 1996. Cell fate determination in the vertebrate retina. Proc. Natl. Acad. Sci. 93: 589-595.

Chenn, A. and Walsh, C.A. 2002. Regulation of cerebral cortical size by control of cell cycle exit in neural precursors. Science 297: 365-369.

Collignon, J., Sockanathan, S., Hacker, A., Cohen-Tannoudji, M., Norris, D., Rastan, S., Stevanovic, M., Goodfellow, P.N., 
and Lovell-Badge, R. 1996. A comparison of the properties of Sox-3 with Sry and two related genes, Sox-1 and Sox-2. Development 122: 509-520.

Dailey, L., Yuan, H., and Basilico, C. 1994. Interaction between a novel F9-specific factor and octamer-binding proteins is required for cell-type-restricted activity of the fibroblast growth factor 4 enhancer. Mol. Cell. Biol. 14: 7758-7769.

D'Amour, K.A. and Gage, F.H. 2003. Genetic and functional differences between multipotent neural and pluripotent embryonic stem cells. Proc. Natl. Acad. Sci. 100 (Suppl. 1): 11866-11872.

DeKoter, R.P. and Singh, H. 2000. Regulation of B lymphocyte and macrophage development by graded expression of PU.1. Science 288: 1439-1441.

Driver, H.S., McLean, H., Kumar, D.V., Farr, N., Day, A.G., and Fitzpatrick, M.F. 2005. The influence of the menstrual cycle on upper airway resistance and breathing during sleep. Sleep 28: 449-456.

Dyer, M.A. and Cepko, C.L. 2001. Regulating proliferation during retinal development. Nat. Rev. Neurosci. 2: 333-342.

Eisenfeld, A.J., Bunt-Milam, A.H., and Saari, J.C. 1985. Immunocytochemical localization of retinoid-binding proteins in developing normal and RCS rats. Prog. Clin. Biol. Res. 190: 231-240.

Ellis, P., Fagan, B.M., Magness, S.T., Hutton, S., Taranova, O., Hayashi, S., McMahon, A., Rao, M., and Pevny, L. 2004. SOX2, a persistent marker for multipotential neural stem cells derived from embryonic stem cells, the embryo or the adult. Dev. Neurosci. 26: 148-165.

Emambokus, N., Vegiopoulos, A., Harman, B., Jenkinson, E., Anderson, G., and Frampton, J. 2003. Progression through key stages of haemopoiesis is dependent on distinct threshold levels of c-Myb. EMBO J. 22: 4478-4488.

Fantes, J., Ragge, N.K., Lynch, S.A., McGill, N.I., Collin, J.R., Howard-Peebles, P.N., Hayward, C., Vivian, A.J., Williamson, K., van Heyningen, V., et al. 2003. Mutations in SOX2 cause anophthalmia. Nat. Genet. 33: 461-463.

Ferri, A.L., Cavallaro, M., Braida, D., Di Cristofano, A., Canta, A., Vezzani, A., Ottolenghi, S., Pandolfi, P.P., Sala, M., DeBiasi, S., et al. 2004. Sox2 deficiency causes neurodegeneration and impaired neurogenesis in the adult mouse brain. Development 131: 3805-3819.

Fitzpatrick, D.R. and van Heyningen, V. 2005. Developmental eye disorders. Curr. Opin. Genet. Dev. 15: 348-353.

Fujita, S. 2003. The discovery of the matrix cell, the identification of the multipotent neural stem cell and the development of the central nervous system. Cell Struct. Funct. 28: 205-228.

Graham, V., Khudyakov, J., Ellis, P., and Pevny, L. 2003. SOX2 functions to maintain neural progenitor identity. Neuron 39: 749-765.

Hagstrom, S.A., Pauer, G.J., Reid, J., Simpson, E., Crowe, S., Maumenee, I.H., and Traboulsi, E.I. 2005. SOX2 mutation causes anophthalmia, hearing loss, and brain anomalies. Am. J. Med. Genet. A 138: 95-98.

Hatakeyama, J. and Kageyama, R. 2004. Retinal cell fate determination and bHLH factors. Semin. Cell Dev. Biol. 15: 8389.

Hatakeyama, J., Bessho, Y., Katoh, K., Ookawara, S., Fujioka, M., Guillemot, F., and Kageyama, R. 2004. Hes genes regulate size, shape and histogenesis of the nervous system by control of the timing of neural stem cell differentiation. Development 131: 5539-5550.

Henrique, D., Hirsinger, E., Adam, J., Le Roux, I., Pourquie, O., Ish-Horowicz, D., and Lewis, J. 1997. Maintenance of neuroepithelial progenitor cells by Delta-Notch signalling in the embryonic chick retina. Curr. Biol. 7: 661-670.

Ishibashi, M., Moriyoshi, K., Sasai, Y., Shiota, K., Nakanishi, S., and Kageyama, R. 1994. Persistent expression of helix-loophelix factor HES-1 prevents mammalian neural differentiation in the central nervous system. EMBO J. 13: 1799-1805.

Jadhav, A.P., Mason, H.A., and Cepko, C.L. 2006. Notch 1 inhibits photoreceptor production in the developing mammalian retina. Development 133: 913-923.

Kageyama, R., Ohtsuka, T., Hatakeyama, J., and Ohsawa, R. 2005. Roles of bHLH genes in neural stem cell differentiation. Exp. Cell Res. 306: 343-348.

Kamachi, Y., Uchikawa, M., Collignon, J., Lovell-Badge, R., and Kondoh, H. 1998. Involvement of Sox1, 2 and 3 in the early and subsequent molecular events of lens induction. Development 125: 2521-2532.

Kamachi, Y., Cheah, K.S., and Kondoh, H. 1999. Mechanism of regulatory target selection by the SOX high-mobility-group domain proteins as revealed by comparison of $S O X 1 / 2 / 3$ and SOX9. Mol. Cell. Biol. 19: 107-120.

Kamachi, Y., Uchikawa, M., Tanouchi, A., Sekido, R., and Kondoh, H. 2001. Pax6 and SOX2 form a co-DNA-binding partner complex that regulates initiation of lens development. Genes \& Dev. 15: 1272-1286.

Kammandel, B., Chowdhury, K., Stoykova, A., Aparicio, S., Brenner, S., and Gruss, P. 1999. Distinct cis-essential modules direct the time-space pattern of the Pax6 gene activity. Dev. Biol. 205: 79-97.

Kim, J., Lo, L., Dormand, E., and Anderson, D.J. 2003. SOX10 maintains multipotency and inhibits neuronal differentiation of neural crest stem cells. Neuron 38: 17-31.

Kishi, M., Mizuseki, K., Sasai, N., Yamazaki, H., Shiota, K., Nakanishi, S., and Sasai, Y. 2000. Requirement of Sox2-mediated signaling for differentiation of early Xenopus neuroectoderm. Development 127: 791-800.

Kondo, T. and Raff, M. 2004. Chromatin remodeling and histone modification in the conversion of oligodendrocyte precursors to neural stem cells. Genes \& Dev. 18: 2963-2972.

Kulessa, H., Frampton, J., and Graf, T. 1995. GATA-1 reprograms avian myelomonocytic cell lines into eosinophils, thromboblasts, and erythroblasts. Genes \& Dev. 9: 1250-1262.

Labadie, R.F., Shah, R.J., Harris, S.S., Cetinkaya, E., Haynes, D.S., Fenlon, M.R., Juszczyk, A.S., Galloway, R.L., and Fitzpatrick, J.M. 2005. In vitro assessment of image-guided otologic surgery: Submillimeter accuracy within the region of the temporal bone. Otolaryngol. Head Neck Surg. 132: 435442.

Lardelli, M. and Lendahl, U. 1993. Motch A and motch B-Two mouse Notch homologues coexpressed in a wide variety of tissues. Exp. Cell Res. 204: 364-372.

Le, R.D., Rayner, K., Rex, M., Wigmore, P.M., and Scotting, P.J. 2002. The transcription factor cSox2 and Neuropeptide $Y$ define a novel subgroup of amacrine cells in the retina. $J$. Anat. 200: 51-56.

Lee, J.E., Hollenberg, S.M., Snider, L., Turner, D.L., Lipnick, N., and Weintraub, H. 1995. Conversion of Xenopus ectoderm into neurons by NeuroD, a basic helix-loop-helix protein. Science 268: 836-844.

Lewandoski, M., Wassarman, K.M., and Martin, G.R. 1997. Zp3-cre, a transgenic mouse line for the activation or inactivation of loxP-flanked target genes specifically in the female germ line. Curr. Biol. 7: 148-151.

Loosli, F., Koster, R.W., Carl, M., Krone, A., and Wittbrodt, J. 1998. Six3, a medaka homologue of the Drosophila homeobox gene sine oculis is expressed in the anterior embryonic shield and the developing eye. Mech. Dev. 74: 159-164.

Magness, S.T., Tugores, A., Diala, E.S., and Brenner, D.A. 1998. 
Analysis of the human ferrochelatase promoter in transgenic mice. Blood 92: 320-328.

Marquardt, T. and Gruss, P. 2002. Generating neuronal diversity in the retina: One for nearly all. Trends Neurosci. 25: 32-38.

Marquardt, T., Ashery-Padan, R., Andrejewski, N., Scardigli, R., Guillemot, F., and Gruss, P. 2001. Pax6 is required for the multipotent state of retinal progenitor cells. Cell 105: 43-55.

Mizuseki, K., Kishi, M., Matsui, M., Nakanishi, S., and Sasai, Y. 1998. Xenopus Zic-related-1 and Sox-2, two factors induced by chordin, have distinct activities in the initiation of neural induction. Development 125: 579-587.

Motohashi, H., Katsuoka, F., Shavit, J.A., Engel, J.D., and Yamamoto, M. 2000. Positive or negative MARE-dependent transcriptional regulation is determined by the abundance of small Maf proteins. Cell 103: 865-875.

Motohashi, H., Katsuoka, F., Engel, J.D., and Yamamoto, M. 2004. Small Maf proteins serve as transcriptional cofactors for keratinocyte differentiation in the Keap1-Nrf2 regulatory pathway. Proc. Nat1. Acad. Sci. 101: 6379-6384.

$\mathrm{Mu}, \mathrm{X}$., Fu, X., Sun, H., Liang, S., Maeda, H., Frishman, L.J., and Klein, W.H. 2005. Ganglion cells are required for normal progenitor-cell proliferation but not cell-fate determination or patterning in the developing mouse retina. Curr. Biol. 15: 525-530.

Nishiguchi, S., Wood, H., Kondoh, H., Lovell-Badge, R., and Episkopou, V. 1998. Sox1 directly regulates the $\gamma$-crystallin genes and is essential for lens development in mice. Genes \& Dev. 12: 776-781.

O'Brien, P.D., Fitzpatrick, P., and Power, W. 2005. Patient pain during stretching of small pupils in phacoemulsification performed using topical anesthesia. J. Cataract Refract. Surg. 31: 1760-1763.

Pearson, B.J. and Doe, C.Q. 2004. Specification of temporal identity in the developing nervous system. Annu. Rev. Cell Dev. Biol. 20: 619-647.

Pevny, L.H. and Lovell-Badge, R. 1997. Sox genes find their feet. Curr. Opin. Genet. Dev. 7: 338-344.

Pevny, L. and Placzek, M. 2005. SOX genes and neural progenitor identity. Curr. Opin. Neurobiol. 15: 7-13.

Pevny, L.H., Sockanathan, S., Placzek, M., and Lovell-Badge, R. 1998. A role for SOX1 in neural determination. Development 125: 1967-1978.

Polleux, F. and Ghosh, A. 2002. The slice overlay assay: A versatile tool to study the influence of extracellular signals on neuronal development. Sci. STKE 2002: PL9.

Ragge, N.K., Brown, A.G., Poloschek, C.M., Lorenz, B., Henderson, R.A., Clarke, M.P., Russell-Eggitt, I., Fielder, A., Gerrelli, D., Martinez-Barbera, J.P., et al. 2005a. Heterozygous mutations of OTX2 cause severe ocular malformations. Am. J. Hum. Genet. 76: 1008-1022.

Ragge, N.K., Lorenz, B., Schneider, A., Bushby, K., de Sanctis, L., de Sanctis, U., Salt, A., Collin, J.R., Vivian, A.J., Free, S.L., et al. 2005b. SOX2 anophthalmia syndrome. Am. I. Med. Genet. A 135: 1-7.

Reh, T.A. and Fischer, A.J. 2001. Stem cells in the vertebrate retina. Brain Behav. Evol. 58: 296-305.

Rizzoti, K., Brunelli, S., Carmignac, D., Thomas, P.Q., Robinson, I.C., and Lovell-Badge, R. 2004. SOX3 is required during the formation of the hypothalamo-pituitary axis. Nat. Genet. 36: 247-255.

Scaffidi, P. and Bianchi, M.E. 2001. Spatially precise DNA bending is an essential activity of the sox 2 transcription factor. $J$. Biol. Chem. 276: 47296-47302.

Sinor, A.D. and Lillien, L. 2004. Akt-1 expression level regulates CNS precursors. J. Neurosci. 24: 8531-8541.
Tanaka, S., Kamachi, Y., Tanouchi, A., Hamada, H., Jing, N. and Kondoh, H. 2004. Interplay of SOX and POU factors in regulation of the Nestin gene in neural primordial cells. Mol. Cell. Biol. 24: 8834-8846.

Tomita, K., Ishibashi, M., Nakahara, K. Ang, S.L., Nakanishi, S., Guillemot, F., and Kageyama, R. 1996. Mammalian hairy and Enhancer of split homolog 1 regulates differentiation of retinal neurons and is essential for eye morphogenesis. Neuron 16: 723-734.

Tugores, A., Magness, S.T., and Brenner, D.A. 1994. A single promoter directs both housekeeping and erythroid preferential expression of the human ferrochelatase gene. J. Biol. Chem. 269: 30789-30797.

Uchikawa, M., Kamachi, Y., and Kondoh, H. 1999. Two distinct subgroups of Group B Sox genes for transcriptional activators and repressors: Their expression during embryonic organogenesis of the chicken. Mech. Dev. 84: 103-120.

Uchikawa, M., Ishida, Y., Takemoto, T., Kamachi, Y., and Kondoh, H. 2003. Functional analysis of chicken Sox2 enhancers highlights an array of diverse regulatory elements that are conserved in mammals. Dev. Cell 4: 509-519.

Van Raay, T.J., Moore, K.B., Iordanova, I., Steele, M., Jamrich, M., Harris, W.A., and Vetter, M.L. 2005. Frizzled 5 signaling governs the neural potential of progenitors in the developing Xenopus retina. Neuron 46: 23-36.

Waid, D.K. and McLoon, S.C. 1995. Immediate differentiation of ganglion cells following mitosis in the developing retina. Neuron 14: 117-124.

Weinmann, A.S. and Farnham, P.J. 2002. Identification of unknown target genes of human transcription factors using chromatin immunoprecipitation. Methods 26: 37-47.

Weinmann, A.S., Yan, P.S., Oberley, M.J., Huang, T.H., and Farnham, P.J. 2002. Isolating human transcription factor targets by coupling chromatin immunoprecipitation and $\mathrm{CpG}$ island microarray analysis. Genes \& Dev. 16: 235-244.

Weiss, J., Meeks, J.J., Hurley, L., Raverot, G., Frassetto, A., and Jameson, J.L. 2003. Sox3 is required for gonadal function, but not sex determination, in males and females. Mol. Cell. Biol. 23: 8084-8091.

$\mathrm{Xu}, \mathrm{X}$. , Bosking, W.H., White, L.E., Fitzpatrick, D., and Casagrande, V.A. 2005. Functional organization of visual cortex in the prosimian bush baby revealed by optical imaging of intrinsic signals. J. Neurophysiol. 94: 2748-2762.

Yang, Z., Ding, K., Pan, L., Deng, M., and Gan, L. 2003. Math5 determines the competence state of retinal ganglion cell progenitors. Dev. Biol. 264: 240-254.

Zappone, M.V., Galli, R., Catena, R., Meani, N., De Biasi, S., Mattei, E., Tiveron, C., Vescovi, A.L., Lovell-Badge, R., Ottolenghi, S., et al. 2000. Sox2 regulatory sequences direct expression of a $(\beta)$-geo transgene to telencephalic neural stem cells and precursors of the mouse embryo, revealing regionalization of gene expression in CNS stem cells. Development 127: 2367-2382.

Zenteno, J.C., Gascon-Guzman, G., and Tovilla-Canales, J.L. 2005. Bilateral anophthalmia and brain malformations caused by a 20-bp deletion in the SOX2 gene. Clin. Genet. 68: $564-566$.

Zhang, J., Gray, J., Wu, L., Leone, G., Rowan, S., Cepko, C.L., Zhu, X., Craft, C.M., and Dyer, M.A. 2004. Rb regulates proliferation and rod photoreceptor development in the mouse retina. Nat. Genet. 36: 351-360.

Zhuang, Y., Jackson, A., Pan, L., Shen, K., and Dai, M. 2004. Regulation of E2A gene expression in B-lymphocyte development. Mol. Immunol. 40: 1165-1177.

Zigman, S. and Paxhia, T. 1988. The nature and properties of squirrel lens yellow pigment. Exp. Eye Res. 47: 819-824. 


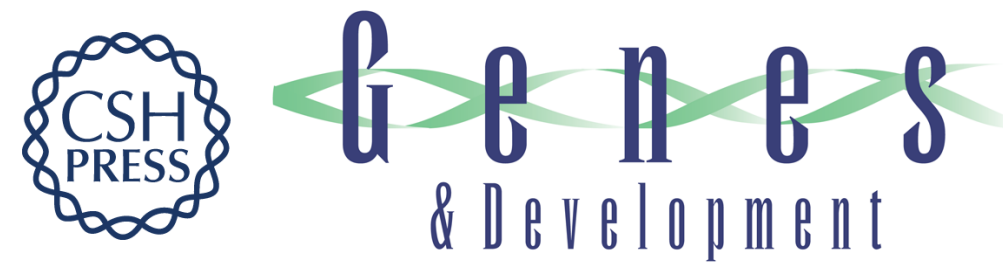

\section{SOX2 is a dose-dependent regulator of retinal neural progenitor competence}

Olena V. Taranova, Scott T. Magness, B. Matthew Fagan, et al.

Genes Dev. 2006, 20:

Access the most recent version at doi:10.1101/gad.1407906

Supplemental http://genesdev.cshlp.org/content/suppl/2006/04/17/20.9.1187.DC1
Material

References This article cites 78 articles, 30 of which can be accessed free at: http://genesdev.cshlp.org/content/20/9/1187.full.html\#ref-list-1

License

Email Alerting Receive free email alerts when new articles cite this article - sign up in the box at the top Service right corner of the article or click here.

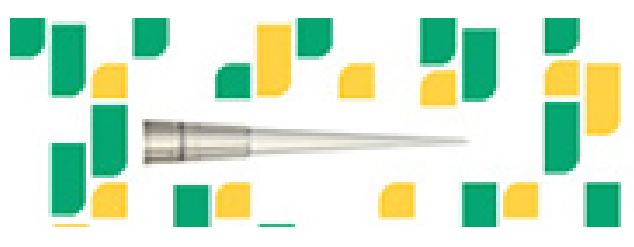

